\title{
El poblamiento ibérico en el Alto Guadiana
}

\section{The Iberian settlement in the Upper Guadiana Basin}

\author{
Rosario García Huerta*, Javier Morales Hervás** \\ Departamento de Historia, Universidad de Castilla-La Mancha, Ciudad Real. \\ *Rosario.Garcia@uclm.es \\ **Fco.Morales@uclm.es
}

\section{RESUMEN}

En este trabajo se presentan los resultados de las investigaciones recientes realizadas sobre la época ibérica en el Alto Guadiana, provincia de Ciudad Real (Castilla-La Mancha). Se incluyen los trabajos de excavación y prospección arqueológica llevados a cabo en esta zona, desde hace dos décadas, que han permitido plantear el modelo de poblamiento en este territorio durante el desarrollo de la cultura ibérica.

Palabras Clave: Alto Guadiana. Cultura Ibérica. Poblamiento. Territorio. Asentamientos.

\begin{abstract}
This paper presents the results of the recent research on the Iberian Iron Age sites conducted in the Upper Guadiana basin of the Ciudad Real province (Castilla-La Mancha). The research included excavations and archaeological surveys conducted in this area for two decades, setting up the foundation of a model of settlement in this territory during the development of the Iberian culture.
\end{abstract}

KEY WoRDs: Upper Guadiana basin. Iberian culture. Demography. Territory. Settlement.

Sumario 1. Introducción. 2. La evolución cultural. 3. Modelo de Poblamiento. 4. Conclusiones. 


\section{Introducción}

Los estudios sobre el mundo ibérico en esta región (Fig. 1) son relativamente recientes, pues se inician en los años setenta con los trabajos arqueológicos del yacimiento de Oreto en Granátula de Calatrava, pero será en los años ochenta, con el comienzo de las excavaciones de una serie de yacimientos ibéricos como Alarcos en Ciudad Real, el Cerro de las Cabezas en Valdepeñas, La Bienvenida en Almodóvar del Campo y el Cerro de las Nieves en Pedro Muñoz, cuando se produzca un salto cualitativo en la investigación sobre este período; les siguen los trabajos arqueológicos desarrollados en las motillas de las Cañas en Daimiel, los Palacios en Almagro y del Retamar en Argamasilla de Alba, en la ciudad islámica de Calatrava la Vieja en Carrión de Calatrava y la necrópolis de Alhambra que, a pesar de no haberse centrado en los niveles ibéricos, han aportado interesantes elementos que permiten vislumbrar la importancia del período ibérico en dichos asentamientos. Por último debemos citar las campañas de excavación llevadas a cabo en el poblado protohistórico de Peñarroya en Argamasilla de Alba en 1994 y 1995, y los trabajos arqueológicos iniciados en 1998 en el yacimiento de Villanueva de la Fuente, que permitirán obtener importantes datos sobre la iberización de este territorio. Estos trabajos se complementaron con una importante labor de prospección que desde comienzos de los noventa fue impulsada por la Consejería de Educación y Cultura de la comunidad autónoma y la

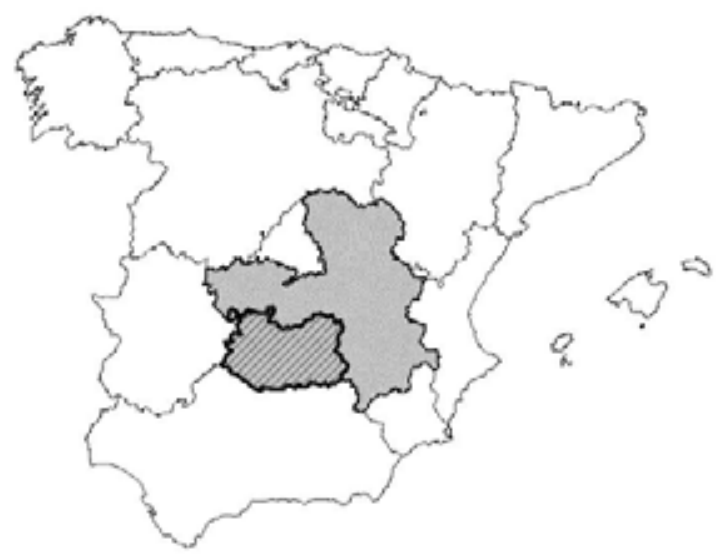

Figura 1.- Situación de la provincia de Ciudad Real, objeto del estudio, en el marco de la Comunidad de Castilla la Mancha y España.
Universidad de Castilla-La Mancha con el objeto de iniciar la elaboración de la Carta Arqueológica de la provincia de Ciudad Real, proyecto que está permitiendo la localización de un notable número de nuevos yacimientos ibéricos.

A diferencia de otras áreas limítrofes en las que se han realizado estudios sobre el poblamiento ibérico (Berrocal-Rangel 1992; Rodríguez Díaz 1995; Soria 2000; Bonet y Mata 2001; Grau 2002) en nuestra zona la falta de datos relevantes existente hasta hace muy poco tiempo ha impedido poder abordar este tipo de trabajos. Con todo, disponemos de varios estudios que abordan aspectos concretos de la época ibérica en esta zona, como el de Almagro Gorbea (1977) que establecía una división de la parte oriental de la Meseta Meridional en nueve áreas culturales, dos de las cuales, -Valdepeñas y el área manchega-, corresponden al ámbito territorial que aquí tratamos. Su importancia deriva, básicamente, de su carácter pionero, ya que constituyó un punto de partida y presentó por vez primera una visión global sobre el proceso de iberización en una zona en la que había, en aquellos momentos, escasos datos acerca de su etapa protohistórica.

Posteriormente López Rozas (1987) estableció una división diferente de la meseta meridional en seis ámbitos culturales, de los que dos se enmarcan en la provincia de Ciudad Real: la zona del Campo de Calatrava-estribaciones de Sierra Morena y la Mancha Central. Este estudio manifiesta un buen conocimiento del área geográfica analizada y de los yacimientos en ella ubicados, pues la realización de prospecciones en parte de la zona estudiada, -curso bajo del Cigüela, Tablas de Daimiel y estribaciones meridionales de los Montes de Toledo-, le permitieron obtener datos de primera mano.

En tercer lugar es preciso citar el trabajo de Blasco (1992) que actualizaba el análisis global de Almagro Gorbea con los datos obtenidos en la década de los años 80 de las excavaciones de Alarcos y del Cerro de las Cabezas. En él se hace especial hincapié en la cuestión del proceso formativo de la cultura ibérica en la meseta meridional, donde se constata la temprana presencia de lo ibérico en las tierras más meridionales de la zona estudiada. Más recientemente hay que destacar la tesis doctoral elaborada por uno de nosotros (Morales, 2010) en la que se recogen todos los datos procedentes de las excavaciones de yacimientos ibéricos 
de la zona junto con las prospecciones realizadas por todo el territorio que han permitido elaborar una hipótesis sobre el poblamiento en esta zona que presentamos resumidamente en este artículo.

Por otra parte, no podemos olvidar una serie de trabajos centrados en el análisis de yacimientos arqueológicos que, total o parcialmente, se inscriben dentro del período ibérico (Fig. 2), como es el caso de Oreto (Nieto et al. 1980), La Bienvenida (Fernández Ochoa et al. 1994; Zarzalejos et al. 1994, 2004), la Motilla de Las Cañas (Molina et al. 1983), la Motilla de los Palacios (Fernández Rodríguez y Fonseca 1985), Alarcos (De Juan et al. 1994; Fernández Rodríguez et al. 1995; García Huerta et al. 2004), el Cerro de las Cabezas (Vélez y Pérez Avilés 1987), el Cerro de las Nieves (Fernández Martínez 1988; Fernández Martínez et al. 1994) y el poblado de Peñarroya (García Huerta et al. 1999).

\section{La evolución cultural}

\subsection{La etapa preibérica}

El Alto Guadiana contaba con un importante poblamiento, al menos desde comienzos del II milenio a.C., estructurado a partir de diferentes tipos de poblados -castellones, motillas, fondos de cabaña, etc.-, que responderían a diferentes procesos de adaptación al medio por parte de los distintos grupos asentados en este área, los cuales ya manifestaban una evidente apertura hacia el exterior al mostrarse receptivos a las influencias culturales llegadas desde otros ámbitos como, por ejemplo, el mundo argárico.

Hacia finales del II milenio a.C. parece producirse una cierta ruptura dentro de la evolución cultural experimentada por el denominado Bronce Manchego, que se pone de manifiesto a través del cambio producido en el patrón de poblamiento al

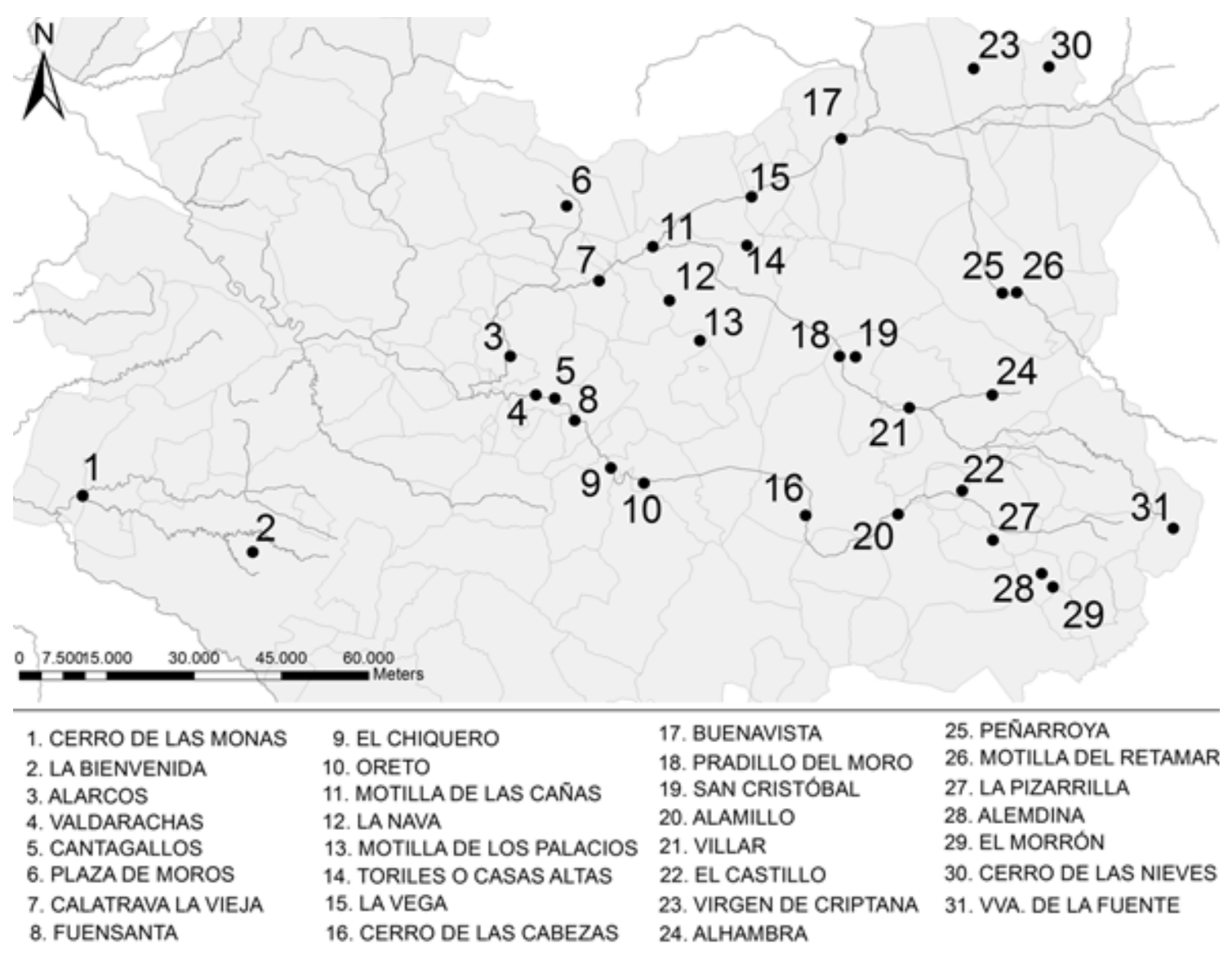

Figura 2.- Mapa de dispersión de los yacimientos citados en el texto, dentro de la provincia de Ciudad Real. 
abandonarse en un corto espacio de tiempo la práctica totalidad de los anteriores asentamientos, básicamente castellones y motillas. Este fenómeno, similar al producido en otros lugares, supone la aparición de nuevos asentamientos, la mayor parte de ellos ex novo, que se localizan normalmente en cotas más bajas que los poblados de altura de la etapa anterior, cerca de las zonas de vega y mostrando un gran interés por controlar los recursos agrarios y las vías de comunicación del entorno.

La reorganización en la ocupación del territorio será exitosa y dará respuesta a los grupos indígenas durante un dilatado período de tiempo, pues los nuevos asentamientos mantendrán, en la mayor parte de los casos, una continuidad en la ocupación hasta los momentos finales del mundo ibérico, llegando incluso a romanizarse buena parte de ellos. Este cambio en el patrón de asentamiento será realizado por las mismas gentes del Bronce Manchego que reaccionan modificando la estructura de ocupación del territorio, posiblemente como respuesta a las transformaciones que se producen en el Bronce Final ante la intensificación económica que se genera en diversas zonas peninsulares fruto de la aceleración en los intercambios bajo el impulso atlántico, en un primer momento, y el mediterráneo en una segunda fase. De este modo, podemos afirmar que, entre finales del II milenio y principios del I milenio a.C., se produce sobre el sustrato indígena, heredero del Bronce Manchego, la interacción de diversas tradiciones culturales que llegan a esta zona tamizadas y reinterpretadas tras su paso por áreas limítrofes como la Meseta Norte, el Suroeste, el Sudeste y la Alta Andalucía. Como consecuencia de ello se inicia un proceso que acabará cristalizando en la iberización de las poblaciones aquí asentadas. Hasta hace una década el conocimiento sobre el Bronce FinalHierro I en el Alto Guadiana presentaba una gran laguna, pues parecía que después del Bronce Medio, con el abandono de los poblados antes citados del Bronce Manchego, se producía en esta zona un despoblamiento casi generalizado que prácticamente duraba hasta la iberización. Sin embargo, en la actualidad, gracias a las investigaciones realizadas, hemos podido identificar una serie de yacimientos en los que empieza a documentarse un horizonte de fines del Bronce Final-I Edad del Hierro, definido por cerámicas a mano decoradas con motivos pintados, bruñidas, incisas, grafitadas e impresas.
Los yacimientos con materiales arqueológicos de esa época en la provincia de Ciudad Real no son aún numerosos, pero resulta significativo que se encuentren repartidos y mostrando una distribución bastante homogénea, que parece indicar una ocupación racional y más concentrada del territorio. Uno de los elementos que pueden ser tomados en cuenta a la hora de proponer una cierta concentración poblacional en los inicios de este proceso de cambio de patrón en la ocupación del territorio es el hecho de que entre los nuevos emplazamientos elegidos se encuentren yacimientos de grandes dimensiones, que con posterioridad se convertirán, en la mayor parte de los casos, en los principales oppida de época ibérica. Es el caso de La Bienvenida, Alarcos, Cerro de las Cabezas, Almedina, etc. Aunque no podemos precisar la superficie ocupada en estos poblados durante la etapa del Bronce Final-Hierro I, las excavaciones arqueológicas realizadas en Alarcos y el Cerro de las Cabezas permiten afirmar que debió de ser considerable -varias hectáreas- ya que se ha podido constatar la presencia de materiales y estructuras correspondientes a este período en distintas áreas de esos asentamientos.

Estos grandes poblados, que empiezan a configurarse entre finales del II milenio y comienzos del I milenio a.C., responden a dos tipologías básicas. Por un lado encontramos los que se ubican sobre pequeñas elevaciones que sobresalen entre 5 y 12 $\mathrm{m}$ sobre el terreno circundante -La Bienvenida, Calatrava la Vieja-, y que sin presentar una destacada diferencia de altitud tienen un amplio control visual sobre las amplias zonas llanas del entorno. El segundo tipo está representado por grandes asentamientos localizados sobre cabezos más o menos amesetados, que se elevan notablemente con respecto al terreno circundante -Alarcos, Cerro de las Cabezas, Almedina-, gozando de este modo de una destacada posición estratégica que les permitiría ejercer un extenso control territorial. Aunque su elevada posición les otorgaba una cierta defensa natural, es habitual que este tipo de poblados cuenten con estructuras defensivas artificiales.

El yacimiento de Alarcos está emplazado en un cerro de grandes dimensiones, bien defendido de forma natural por sus vertientes norte y oeste, que se eleva sobre el valle medio del Guadiana. Su ubicación permite el control de las vías de comunicación entre este territorio y la meseta norte y con 
Andalucía. A las ventajas de su situación estratégica se añaden las posibilidades de la explotación agropecuaria del valle que se extiende a su alrededor, que permitió la ocupación del cerro desde la Edad del Bronce hasta prácticamente nuestros días (Fig. 3). El horizonte del Bronce Final-Hierro I de Alarcos estaría definido por la cerámica de Boquique, el tipo Carambolo, retícula bruñida, pintadas bícromas en color rojo y amarillo, monocromas en color rojo, con incrustaciones de bronce, incisas e impresas (Fig. 4). Estos tipos cerámicos se encuentran prácticamente en todas las áreas del yacimiento que han sido objeto de excavación, lo que indica que se trata de un asentamiento de grandes dimensiones, en torno a las 12 ha (García Huerta y Fernández Rodríguez 2000: 65). Los trabajos arqueológicos llevados a cabo en la ladera sur del yacimiento han permitido documentar un nivel de ocupación preibérico caracterizado por cerámicas pintadas y de retícula bruñida, que se ha fechado por C-14 en los siglos IX y VIII a.C. En este nivel se han identificado varias estructuras de habitación, dos de ellas en curso de excavación, en una de las cuales se conserva un hogar circular formado por una capa de arcilla, de $120 \mathrm{~cm}$ de diámetro y $26 \mathrm{~cm}$ de potencia, que apareció rodeada de piedras de pequeño tamaño.

La Bienvenida se sitúa sobre un cerro ligeramente elevado sobre el terreno circundante lo que le confiere buenas condiciones de visibilidad. El asentamiento está rodeado por una muralla que delimita una extensión de unas 10 ha. Los trabajos arqueológicos han puesto de manifiesto una ocupación desde el s. VIII a.C. hasta el s. IV d.C. La primera ocupación se situaría en un momento de transición entre el Bronce Final-Hierro I (Zarzalejos et al. 2004:166) y se caracteriza por las cerámicas a mano con decoración bruñida y cerámicas pintadas monocromas en color rojo. A un momento más avanzado -mediados del s. VII a.C.- corresponderían las cerámicas a mano pintadas monocromas en color rojo, bícromas y de tipo Medellín. En esta fase, que ha sido denominada por sus investigadores como orientalizante, aparecen las cerámicas grises a torno.

De esta etapa se han identificado restos de construcciones que permiten señalar que las casas construidas entre mediados del siglo VII y el VI a.C. eran sencillas habitaciones con un zócalo de piedras sobre el que se levantaban paredes de tapial o adobe (Zarzalejos et al. 2004: 167). El rasgo cultu-

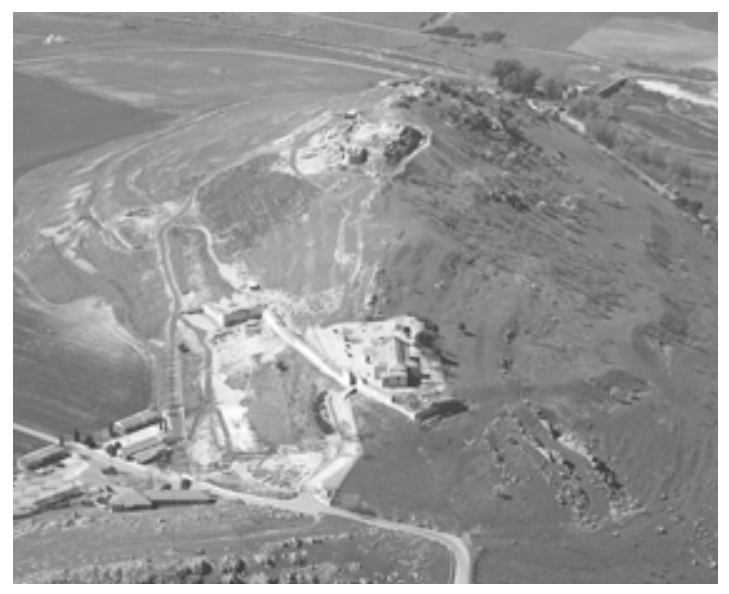

Figura 3.- Vista aérea del yacimiento de Alarcos (Ciudad Real) (Foto archivo Antonio de Juan).
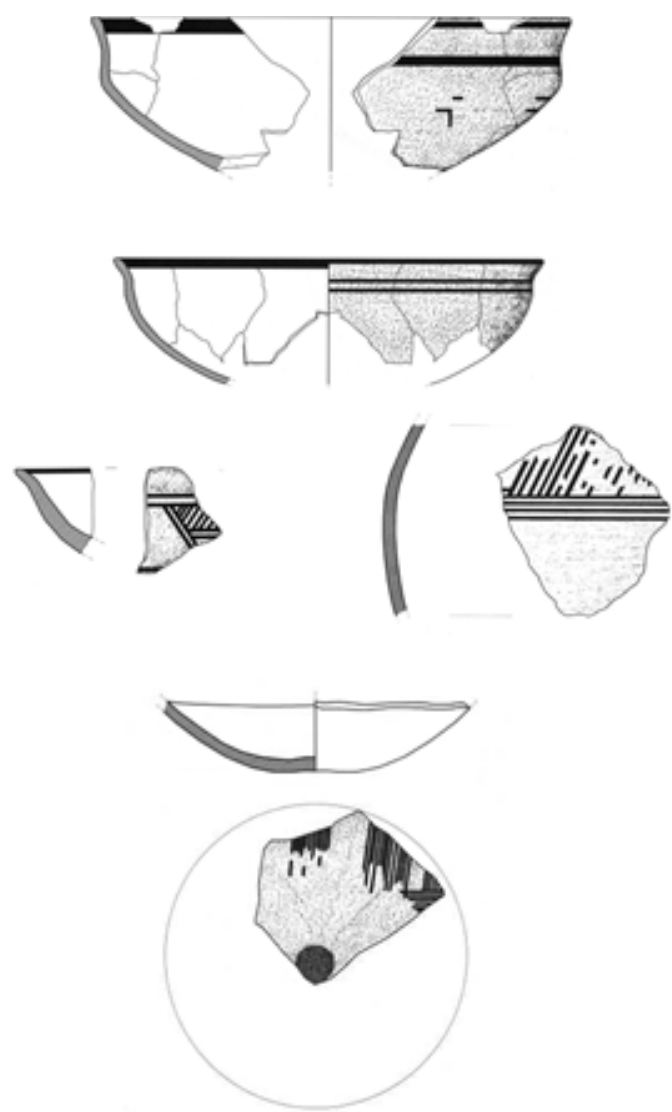

Figura 4.- Cerámicas a mano pintadas de Alarcos (Ciudad Real).

ral más destacable de este momento es la inclusión de La Bienvenida en lo que se denomina "área periférica tartésica", dada la similitud de los mate- 
riales arqueológicos con los que caracterizan al complejo material tartésico del Suroeste, y que vendría justificada por la riqueza minera del territorio en que se ubica el yacimiento, especialmente en cinabrio y plata.

El Cerro de las Cabezas (Valdepeñas) (Fig. 5) se eleva sobre una amplia vega favoreciendo el control del territorio y posibilita una rica actividad agropecuaria en el valle del río Jabalón. Al igual que en los otros dos yacimientos citados, en éste la primera ocupación se produce en un momento de tránsito entre el Bronce Final y el Hierro I. Los materiales arqueológicos están representados por cerámicas a mano con una gran variedad de formas y de motivos decorativos. A una segunda fase de este mismo momento cultural corresponderían las cerámicas a mano, bruñidas, acanaladas y pintadas, en blanco sobre fondo rojo. Estas cerámicas se han encontrado asociadas a estructuras de habitación que se sitúan en la parte más baja de la ladera sur del cerro, junto al río Jabalón. (Vélez y Pérez Avilés 1987).

Otro yacimiento en el que se documenta este horizonte cultural es Calatrava la Vieja (Carrión de Calatrava) (Fig. 6). Ocupa un pequeño cerro amesetado de forma ovalada de unas 5 ha (Retuerce 1994), donde se están realizando excavaciones arqueológicas desde 1984, fundamentalmente en la zona de muralla y arrabales de la ciudad islámica, que han aportado materiales ibéricos, e incluso griegos, procedentes de los tapiales islámicos. En la campaña de excavación llevada a cabo en 1998, al excavar una de las habitaciones del interior de la fortaleza apareció un nivel ibérico y otro de cerámicas a mano bruñidas que correspondería a este momento del Bronce Final-Hierro I.

Junto a los anteriores cabría citar también los asentamientos de Almedina, la Pizarrilla, Alcubillas y Casa de Rana, donde los trabajos de prospección (Pérez Avilés 1985; Pérez 1987) han permitido el hallazgo de materiales cerámicos adscribibles a este momento cultural.

Hasta hace pocos años, prácticamente el único material arqueológico de nuestra zona de estudio que con cierta seguridad podía ser adscrito a esta fase del Bronce Final-Hierro I eran las estelas del sudoeste halladas en diversos lugares de la provincia de Ciudad Real. Se trata de los ejemplares de Aldea del Rey I, II y III, Pozuelo de Calatrava, Alamillo, Chillón, La Bienvenida I y II, que pueden ser agrupados en dos áreas bien diferenciadas:

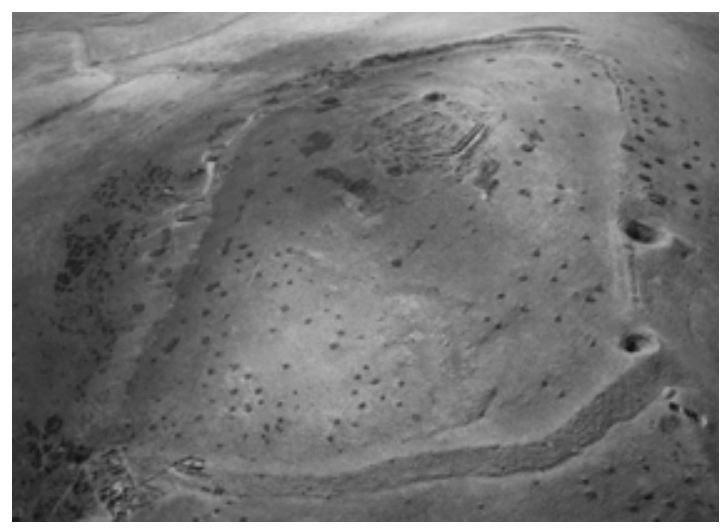

Figura 5.- Vista aérea del Cerro de las Cabezas (Valdepeñas).

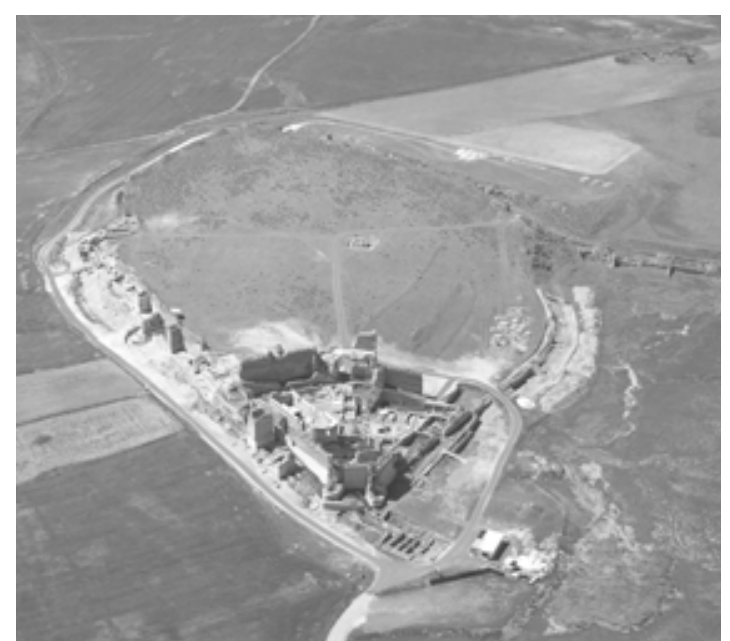

Figura 6.- Vista aérea de Calatrava la Vieja (Carrión de Calatrava) (Foto archivo Antonio de Juan).

el valle medio del río Jabalón y el Valle de Alcudia. En ambos conjuntos aparecen representados los elementos habituales que sirven para definir y clasificar las estelas, como escudos, espadas, lanzas, cascos, fíbulas, espejos, peines, carros, figuras humanas, etc., pero se pueden establecer ciertas diferencias entre un grupo y otro: peines, cascos, escudos redondos y espadas al cinto sólo aparecen representados en el área del Valle de Alcudia, mientras que los carros tan sólo se documentan en el Valle Medio del Jabalón.

También al Bronce Final corresponderían las cerámicas de Cogotas I aparecidas en diversos lugares como Alarcos, Plaza de Moros y Alcázar de San Juan. Dentro de esta misma etapa, y probablemente pertenecientes a un momento más avanzado, debemos incluir otros materiales entre los 
que destacan un hacha de apéndices laterales procedente de Porzuna, un hacha de talón y anillas laterales y otra de apéndices laterales halladas en el paraje de El Embocadero de Torralba de Calatrava (Ciudad y Serrano 1986: 25), la cerámica tipo Carambolo de Alarcos, un conjunto votivo de armas de clara filiación atlántica recuperado en Puertollano (Fernández Rodríguez y Rodríguez de la Esperanza 2002; Montero et al. 2002)) y un brazalete de oro procedente del Valle de Alcudia (Almagro Gorbea 1977: 54-56).

Entre finales del siglo VIII y principios del VI a.C. se pueden diferenciar dos momentos, uno que supone una paulatina transición con respecto al Bronce Final y otro en el que los influjos llegados desde el Mediterráneo son más evidentes, lo que acabará por impulsar el proceso de iberización. La primera fase, que correspondería al Hierro I Inicial, está representada en La Bienvenida, Alarcos y el Cerro de las Cabezas, donde se han documentado niveles arqueológicos cuyos elementos más característicos son cazuelas con una cuidadosa decoración interna bruñida, cerámicas grafitadas y decoradas con pintura post-cocción de colores rojos, blancos y amarillos.

Aunque la mayor parte de la información procede de los yacimientos antes mencionados, también se han recuperado materiales que pueden ser adscritos a este momento en otros yacimientos como Almedina, Villanueva de la Fuente y La Pizarrilla (Cózar). También es importante resaltar el hallazgo fortuito de una serie de recipientes cerámicos en el paraje de La Vega (Arenas de San Juan), concretamente tres cazuelas y un pequeño vasito de cuello fuertemente carenado que muy probablemente procedían de una necrópolis de incineración y que fueron fechados por Nájera y Molina (1977: 279) hacia el 700 a.C., lo que permite datar la llegada del ritual de incineración a estas tierras, al menos, en una fase correspondiente al Hierro I Inicial.

A partir de mediados del siglo VII a.C. se iniciaría la segunda fase o Hierro I Avanzado, que se caracteriza por una incidencia más intensa del denominado influjo "orientalizante". En esta fase se mantienen tipos cerámicos que ya estaban presentes en la etapa anterior como cerámicas bruñidas, grafitadas, pintadas, almagras, pero se incorporan nuevos elementos, especialmente la cerámica a torno entre la que destaca la cerámica gris y, en menor medida, la cerámica de barniz rojo y la cerámica griega. También a este momento pueden adscribirse las fíbulas de doble resorte encontradas en el Cerro de las Cabezas y Alarcos.

La etapa preibérica supone una fase de importancia crucial para poder entender el proceso de iberización y la evolución cultural de las poblaciones asentadas en nuestro ámbito de estudio, ya que es en este período de formación cuando empiezan a configurarse los elementos que definirán las características de las gentes que ocuparán más tarde la denominada Oretania Septentrional. A finales del II milenio a.C. y, sobre todo, en los inicios del I milenio a.C. va tomando forma una organización territorial que constituirá la base del patrón de poblamiento adoptado en época ibérica, con las siguientes características:

-Empiezan a configurarse los grandes poblados que asumirán un especial protagonismo en el control y organización del territorio a partir de época prerromana.

-Se van estructurando las principales vías de comunicación que permitirán conectar esta área del interior peninsular con los focos más dinámicos del litoral facilitando los intercambios comerciales y culturales, rutas que en gran medida tendrán continuidad posteriormente en época romana e incluso durante la Edad Media.

-Se inicia un proceso de intensificación económica basado en la explotación agraria y minera, encaminado a dar respuesta a la creciente demanda exterior con el fin de obtener elementos de prestigio de origen colonial.

-Se empiezan a asumir una serie de novedades tecnológicas y culturales como el torno alfarero, la metalurgia del hierro o el ritual de la incineración de los difuntos.

\subsection{El Período Ibérico}

Los grupos de población asentados en el curso alto del Guadiana que durante el Bronce FinalHierro I habían modificado sus estrategias en la elección de los lugares para establecer sus poblados van a recibir desde fechas muy tempranas la llegada de influencias mediterráneas que rápidamente son asimiladas, lo cual posibilitará que, ya desde finales del s.VI a.C., gran parte de este territorio esté integrado en el ámbito cultural ibérico, en clara conexión con el sudeste peninsular y la Alta Andalucía.

En el proceso de iberización de este territorio 
debió de desempeñar un papel importante el desarrollo experimentado por el flujo comercial a través de las rutas de esta zona sobre todo en su parte más meridional. El colapso económico que padece el área del Sudoeste de la Península y la fundación de Emporion van a favorecer el reajuste de las rutas comerciales por el interior de la Península en función de los intereses griegos que pretenden beneficiarse de la riqueza minera de Sierra Morena y Extremadura. Para ello se utilizaría la ruta que une Levante con Extremadura a través de Albacete y Ciudad Real con una desviación hacia Cástulo.

A partir de finales del siglo VI a.C. asistimos a la progresiva consolidación de la cultura ibérica en este territorio de la Meseta Meridional. Por lo que respecta a la cultura material la denominada cerámica ibérica comienza a adquirir un creciente protagonismo, pero, de forma paralela, se aprecian otros cambios como la mayor complejidad que adoptan las estructuras urbanas, el desarrollo de una diversificada organización económica o la incorporación de la escultura en el ámbito funerario.

\section{Período Ibérico Antiguo}

Este período está representado en los yacimientos citados en el apartado anterior que continúan su desarrollo en esta nueva etapa. En La Bienvenida (Zarzalejos et al. 2004) esta fase se caracterizar por las cerámicas a torno, que constituyen algo menos del $50 \%$, de pastas oxidantes con motivos pintados típicamente ibéricos como círculos, líneas onduladas y bandas anchas. A diferencia de la etapa anterior cuando el repertorio material muestra una clara vinculación con la Baja Andalucía, el conjunto de este momento presenta una gran semejanza con los materiales arqueológicos de la Alta Andalucía, Levante y sureste de la meseta lo que indicaría una nueva orientación en la red de intercambios comerciales motivada por nuevos planteamientos económicos, generados por la crisis del área tartésica.

La fase del Ibérico Antiguo también se documenta en Alarcos donde en las últimas décadas del s.VI a.C. se encuentran cerámicas griegas como el fragmento de un excepcional vaso ático de figuras negras, varios fragmentos de una copa ática o samia y de una copa tipo "C" (García Huerta et al. 2004). La temprana presencia de materiales griegos en estos dos yacimientos pone de manifiesto que ambos recibieron influencias griegas desde los primeros momentos de la iberización, lo que inci- diría, muy posiblemente, en una aceleración de este proceso.

El yacimiento donde mejor representado está el Ibérico Antiguo es el Cerro de las Cabezas, poblado en el que se aprecia el empleo de materiales más resistentes para la construcción de las estructuras urbanas y se produce una modificación significativa con respecto a la etapa anterior al adosarse unas habitaciones a otras configurando conjuntos más amplios, hecho que puede ser entendido como un incipiente intento de ordenación urbana.

En este período surgen nuevos asentamientos como el Cerro de las Nieves en Pedro Muñoz (Fernández Martínez 1988; Fernández et al. 1994) y el poblado de Peñarroya en Argamasilla de Alba (García Huerta et al. 1999). El Cerro de las Nieves se ocuparía entre finales del siglo VI y comienzos del s. V a.C. y desde el primer momento se caracterizaría por cerámicas a mano, junto con cerámicas a torno que alcanzan ya un alto porcentaje (Fernández Martinez et al. 1994: 118).

El poblado de Peñarroya se emplaza en un cerro muy bien dotado de defensas naturales. Su ubicación, controlando el valle del Guadiana, refleja su interés estratégico. Las dos campañas arqueológicas llevadas a cabo en el yacimiento permitieron definir una fase de ocupación situada cronológicamente en los siglos VI y V a.C. (García Huerta et al. 1999), caracterizada por la presencia mayoritaria de cerámicas a mano con una gran variedad de motivos decorativos como impresiones, incisiones y grafitadas; en menor porcentaje está representada la cerámica a torno. Estos materiales se hallaron asociados a estructuras de habitación de planta rectangular, construidas con un zócalo de piedra de mampostería sobre el que descansarían los muros de adobes. La vivienda $\mathrm{n}^{\circ} 1$ (Fig. 7), con unas dimensiones de $20 \mathrm{~m}^{2}$, se hallaba adosada a otra vivienda por el muro sur y en el muro norte había una puerta de $1,10 \mathrm{~m}$ de ancho; la prolongación de este muro da lugar a la definición de un pequeño vestíbulo o umbral. En el muro oeste se localizó un banco adosado hecho de adobes y piedras y en la zona central del recinto un hogar de forma circular, formado por la superposición de varias capas de arcilla. La segunda vivienda excavada está exenta, tiene planta rectangular y las mismas dimensiones que la anterior, el acceso a ella se realizaría a través de una puerta de un metro de anchura situada en la parte central del muro sur. 


\section{Período Ibérico Pleno}

La iberización de las poblaciones indígenas en este territorio meseteño es prácticamente total a mediados del siglo V a.C., momento en el se sitúa el inicio del Ibérico Pleno cuando los influjos externos, básicamente mediterráneos, han consolidado un proceso de aculturación interactivo, en el que las gentes aquí asentadas no se limitan a ser meros espectadores sino que irán adaptando su forma de vida, especialmente su organización económica, ante las nuevas exigencias derivadas de una intensificación comercial y cultural con otros ámbitos peninsulares en los que los interlocutores serán bien otros pueblos iberos o bien mercaderes mediterráneos.

La profundización en los intercambios, tanto mercantiles como culturales, se manifiesta en el notable incremento que se percibe en la llegada de productos foráneos. En este sentido resulta especialmente significativa la presencia de materiales cerámicos griegos, que, si bien ya estaban presentes en la fase anterior, será a partir del ibérico pleno cuando experimenten un notable aumento, tanto en el volumen de restos recuperados como en la variedad de tipos y el número de yacimientos en los que se han podido documentar hasta la fecha.

La llegada de este tipo de producciones importadas - cuya plasmación arqueológica son los restos cerámicos, pero que evidentemente remiten a una mayor variedad de productos como aceite, vino, perfumes, etc., de los cuales tan sólo nos queda su continente- se producirá como resultado de un intercambio comercial en el que los metales, dentro del contingente de productos exportados, asumirán un especial protagonismo. La riqueza minera de la región oretana fue destacada por autores grecolatinos como Plinio, Polibio, Posidonio o Livio, quienes realizaron inequívocas descripciones en torno a la abundancia de determinados minerales, sobre todo plata, plomo y mercurio, noticias que han sido confirmadas tanto a través de estudios mineralógicos como de excavaciones arqueológicas, que han permitido demostrar el aprovechamiento desde época antigua de zonas mineras de la provincia de Ciudad Real, especialmente en el área de Sierra Morena y el Valle de Alcudia (Domergue 1967; Fernández Ochoa et al. 1994).

Si bien resulta evidente que el motivo básico del interés comercial de los pueblos mediterráneos en

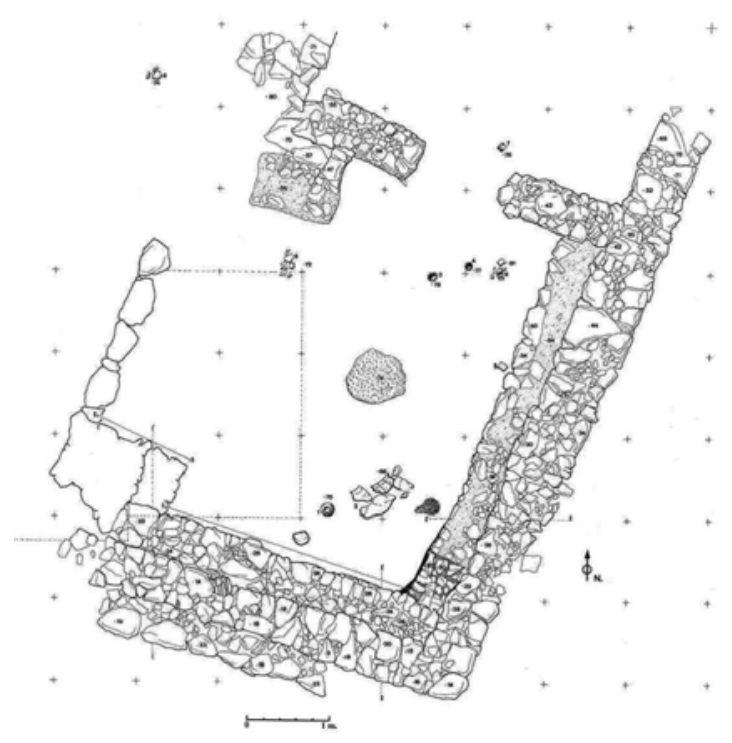

Figura 7.- Vivienda del poblado de Peñarroya (Argamasilla de Alba).

la Península Ibérica era su riqueza mineral, es indudable que, una vez iniciados los intercambios, éstos tuvieron que irse ampliando hacia otro tipo de productos. En este sentido es preciso recordar que esta zona ofrecía en época ibérica unas condiciones adecuadas para atender la demanda foránea en otro tipo de producciones básicas como las de carácter agrario, el esparto o la sal.

Para atender a la creciente demanda exterior de este tipo de productos se tuvieron que producir cambios en la organización interna de los grupos indígenas que habitaban estas tierras, que contribuyeron a reforzar y consolidar el proceso iberizador. Las modificaciones afectaron sobre todo a la estructura socioeconómica y tuvieron como objetivo fundamental lograr una intensificación en la producción con el fin de adaptarse a las exigencias de un sistema de comercio típicamente colonial o asimétrico para poder asegurar la suficiente producción de metales, productos agrarios, sal esparto, pieles, etc. y de este modo satisfacer la demanda de los mercaderes mediterráneos que a cambio aportarán objetos de lujo muy apreciados por las jefaturas indígenas, cuyo control les permitirá consolidar su privilegiada posición.

La plasmación visual de este sistema en el que desempeñan un papel protagonista las aristocracias locales se puede rastrear en nuestro ámbito de trabajo a través de la actuación sobre el espacio, intervención que se orienta en una doble dirección: una 
de carácter más sagrado y otra más netamente humana. En el primer caso nos referimos a la intervención sobre el espacio sacralizado con el fin de plasmar y consolidar la existencia de un poder sociopolítico diferenciado, representado por las aristocracias iberas, que encuentran en el ámbito religioso un campo propicio para manifestar y reproducir su status. Este proceso se puede empezar a rastrear en este territorio de la meseta sudoccidental a partir del análisis de ciertos hallazgos muy significativos. Aunque el conocimiento sobre el mundo funerario ibérico es bastante fragmentario, contamos con elementos como la existencia de restos escultóricos procedentes de posibles áreas de necrópolis en Alarcos, Alhambra y Alcubillas, que permiten plantear que probablemente formarían parte de algunas estructuras de tipo tumular o algún pilar-estela, donde se enterrarían individuos que formarían parte de los grupos dirigentes, que emplearían este tipo de iconografía y tipología funeraria con el fin de sentar las bases de su propia perpetuación.

Por otro lado, debemos tener presente la existencia de áreas cultuales en algunos importantes yacimientos de nuestra zona de estudio, concretamente en los oppida de Alarcos y el Cerro de las Cabezas. En ambos casos se ha podido documentar la presencia de un santuario de carácter urbano que podrían ser encuadrados dentro de la denominación de santuarios cívico-dinásticos, pues si bien pudieron estar destinados a la necesidad de dar respuesta a un culto cotidiano, favorecerían la cohesión social de la población agrupada en el oppidum a la vez que permitirían consolidar la preeminencia ideológica del grupo dirigente allí asentado.

Entre mediados del siglo V y mediados del III a.C. se observa un gran desarrollo de la cultura ibérica en el ámbito del alto Guadiana con un número de asentamientos muy superior al período anterior. Algunos de los poblados más importantes de las fases anteriores continúan su desarrollo y alcanzan en este momento su mayor esplendor como Alarcos y el Cerro de las Cabezas.

En esta etapa documentamos en Alarcos una serie de elementos que permiten considerarle como uno de los asentamientos más importantes del ámbito oretano: posición estratégica, gran extensión y existencia de áreas diferenciadas como residencial, económica, de culto y funeraria. El área residencial se extendería por la mayor parte del cerro, aunque donde mejor se ha documentado ha sido en el sector IV Entrada (Fernández y García Huerta 1998), donde las viviendas articuladas en dos barrios se disponen a ambos lados de una calle principal, de unos $5 \mathrm{~m}$ de anchura y hecha de grandes losas de piedra, siendo el occidental el más ampliamente excavado y donde se han localizado una serie de viviendas que se organizan en torno a dos calles perpendiculares a la vía principal.

Las primeras viviendas excavadas en el barrio oriental (Fernández y García Huerta 1998) ofrecían escasa complejidad, con planta rectangular y una o dos estancias; en algunos casos el tamaño de alguna de las estancias es muy pequeño, situándose en este caso en el fondo de la vivienda a modo de despensa. También se documenta una especie de porche o espacio anejo a la casa destinado a la realización de actividades domésticas. El sistema constructivo consiste en un zócalo de mampostería con el alzado de las paredes de adobe. Los suelos son de arcilla rojiza mezclada con cal y en ocasiones están formados por empedrados de cantos pequeños. Las techumbres se realizaron con materiales ligeros, llegándose a documentar en alguna vivienda restos de vigas de madera, ramajes y barro. Las puertas son simples interrupciones en el muro, que no suelen situarse en la zona central del mismo. En el interior de las viviendas se han hallado hogares circulares u ovales delimitados por piedras y constituidos por una gruesa capa de cenizas.

Más recientemente se han excavado una serie de estructuras de mayor tamaño y complejidad entre las que destaca un edificio que consta de tres habitaciones rectangulares de similares dimensiones, en las que se han documentado hogares y piletas, así como gran cantidad de elementos que parecen indicar su uso, no solo como vivienda sino como lugar de almacenamiento y de transformación de alimentos y de trabajos textiles.

En este yacimiento está muy bien representada el área económica en la ladera sur por un almacén de grandes dimensiones y planta monumental, dedicado al almacenamiento comunal y comercial de grano (García Huerta y Morales 2009). En este almacén, al que estimamos una capacidad de almacenaje mínima de $1200 \mathrm{~m}^{3}$-con lo cual podría contener, al menos, unos $750.000 \mathrm{~kg}$ de cereal, se realizaba también al tratamiento de alimentos, como indica el hallazgo de un horno de pan, más de nueve molinos de rotación y vaivén y una serie de concentraciones de cereales, trigo mayoritariamente y en menor medida cebada, totalmente lim- 
pios, así como cerámicas dedicadas a almacenamiento.

La existencia de un área de culto se ha podido determinar por la localización en una de las terrazas de la vertiente sur de una zona sagrada o "santuario", que ha sido en parte destruido por la construcción de la muralla y un basurero medieval. El "santuario" está constituido por una gran estructura maciza de piedra con un cuerpo superior de adobes, que se halla delimitada en su lado noreste por una calle pavimentada con lajas de caliza. En esta zona se han encontrado materiales arqueológicos muy diversos como fíbulas, punzones, objetos metálicos, dos cabecitas de la diosa Astarté, cerámica de todo tipo pero de gran calidad y más de 60 exvotos de bronce (Caballero y Mena 1987).

El área funeraria de la ciudad está todavía mal documentada. Por el tamaño de la ciudad y el largo espacio de tiempo en que estuvo ocupada es muy posible que contara con varias necrópolis, de las que hasta el momento podemos señalar la existencia de dos. Una, de localización imprecisa, en la que se hallaron esculturas zoomorfas de piedra de indiscutible carácter funerario; la otra, más antigua (Fernández Rodríguez 2001), se situaría en la parte baja de la ladera oriental, donde en la etapa de mayor expansión de este poblado se estableció el conjunto de viviendas anteriormente descrito.

La numerosa presencia de materiales griegos, fenicios y de otros objetos exóticos refleja la importancia del comercio en este momento que, sin duda, se vio favorecido por su posición estratégica. Otros materiales como las cerámicas ibéricas pintadas, cuyo número y variedad hacen pensar en la existencia en Alarcos de un gran centro de producción cerámica; las estampilladas, el conjunto de exvotos en bronce, las esculturas en piedra, etc., elementos todos ellos fechados en un período que va desde fines del siglo V al III a.C., reflejan que éste sería el momento de mayor esplendor del oppidum, que iniciará un notable declive a finales del siglo III a.C., quedando un poblamiento residual en la zona del santuario hasta su total abandono en el I a.C.

Otro asentamiento que conoce ahora su etapa de mayor desarrollo es el Cerro de las Cabezas, que llega a alcanzar una extensión de 14 ha, y donde se documentan, además de las áreas de vivienda, zonas dedicadas a actividades artesanales de producción cerámica y metalúrgica y de almacenamiento. Las cerámicas griegas aparecen por vez primera a fines del $\mathrm{V}$ a.C. pero el momento de mayor esplendor son los siglos IV al III a.C, etapa en la que se generaliza la cerámica griega y la cerámica ibérica conoce un gran desarrollo; especialmente de sus motivos decorativos que se vuelven profusos y barrocos. Especial importancia adquiere también la cerámica estampillada, con más de 100 tipos decorativos diferentes (Fernández Maroto et al. 2007).

Los datos sobre la organización urbana (Fig. 8) de este poblado son todavía escasos pues el único plano urbanístico publicado corresponde a la parte más baja de la ladera sur, junto al río, donde se ha excavado un barrio en el que se han hallado alfares, hornos cerámicos, matrices de estampillas, hornos de pan, almacenes de grano, etc., es decir, toda una serie de elementos que permiten definirlo como un barrio comercial y artesano. Este barrio, remodelado entre los siglos V-IV a.C., se articula en torno a una gran vía de unos $4 \mathrm{~m}$ de anchura, que presenta una dirección noroeste-sureste con un trazado curvilíneo y de la que parten calles radiales. Los recintos tienen planta rectangular, se adaptan a la topografía del terreno y se adosan unos a otros; algunos presentan una planta más compleja ya que constan de tres a cinco estancias; la técnica de construcción consiste en un zócalo de mampostería sobre el que se levantaría un muro de adobes.

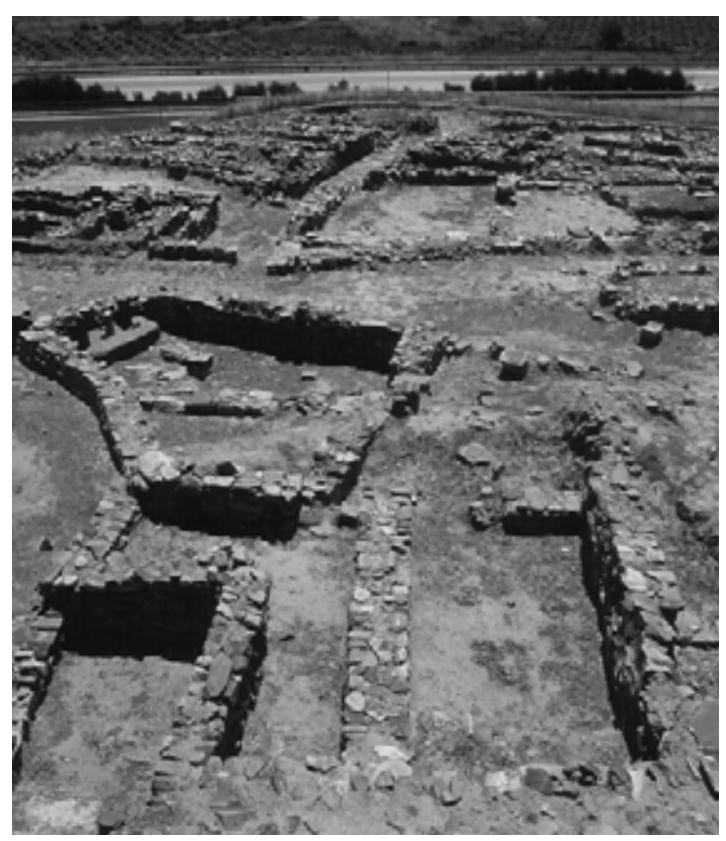

Figura 8.- Viviendas y calle del Cerro de las Cabezas (Valdepeñas). 
Unas son habitaciones dormitorio y otras tienen una clara función económica, habiéndose documentado también un santuario (Vélez et al. 2004). En el último tercio del siglo III a.C. las técnicas constructivas sufren una notable devaluación al emplearse piedras pequeñas poco trabajadas, unidas con abundante argamasa y cal, resultando estructuras muy perecederas. Esta decadencia constructiva parece ser en cierto modo premonitoria pues este oppidum fue destruido de forma violenta a finales del siglo III a.C.

En el yacimiento de La Bienvenida, la fase del Ibérico Pleno se caracteriza por el aumento de las cerámicas ibéricas, que ya predominan claramente sobre las cerámicas a mano, y la presencia de cerámicas griegas (Zarzalejos et al. 2004). En esta fase del ibérico pleno se edificaron viviendas de planta rectangular con un sistema constructivo similar al empleado en épocas anteriores y provistas de hogares de adobe o arcilla.

A los materiales encontrados en la excavación arqueológica de Calatrava la Vieja habría que sumar los restos de cerámica griega procedentes de este yacimiento y depositados en el Museo Provincial de Ciudad Real, que confirmarían su inclusión en la red comercial del momento. A esta etapa es posible que se adscriba un horno formado por dos placas de arcilla endurecida que se apoya en una estructura de piedras de $2 \mathrm{~m}$ de diámetro (Fig. 9).

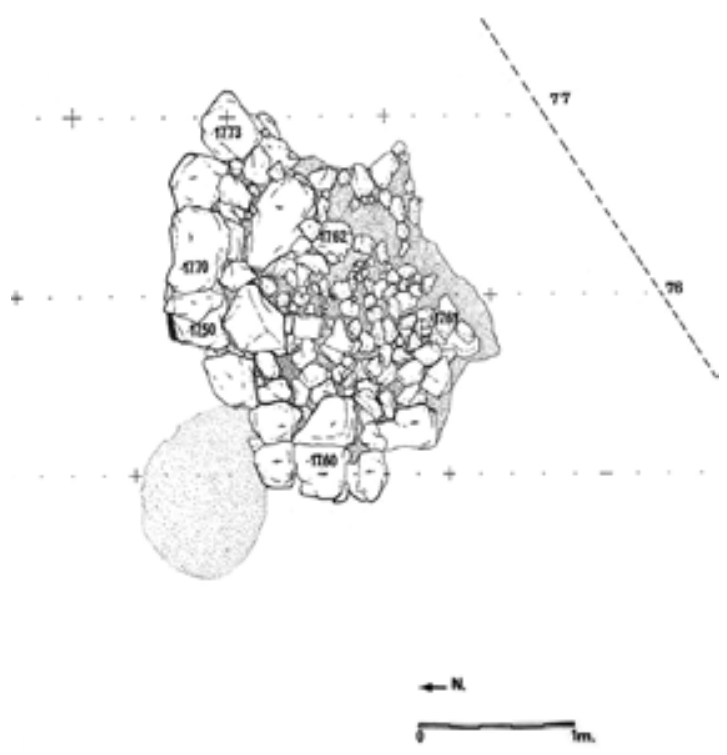

Figura 9.- Horno de Calatrava la Vieja (Carrión de Calatrava).
En el Cerro de la Nieves (Fernández Martínez et al. 1994) durante esta fase hacen su aparición las cerámicas griegas que se adscriben a la segunda mitad del siglo IV o inicios del III a.C., fecha en la que se produciría el abandono del poblado. Este asentamiento de poco más de media hectárea se eleva unos $6 \mathrm{~m}$. sobre el terreno circundante y en él prima la ubicación estratégica: junto a una laguna, próximo a vías de comunicación y en una zona de aprovechamiento agrícola y minero (sal). Las estructuras de habitación documentadas son adosadas de planta rectangular con muros de adobes, mampostería o las dos técnicas combinadas; debido a la inconsistencia de la construcción se produjo el derrumbamiento periódico de las estructuras que, tras un proceso de allanamiento eran de nuevo levantadas, dando al cerro una estructura de tipo tell.

En casi todos los recintos había un hogar que consistía en una masa de arcilla endurecida de forma redonda $u$ ovalada en la que se insertaban fragmentos cerámicos o cantos rodados como aglutinante. En algunos habitáculos había una cubeta o estructura de adobes $\mathrm{y} / \mathrm{o}$ piedras de forma cuadrada y unos $50 \mathrm{~cm}$ de altura, cuya parte superior había sido moldeada con arcilla -varias capas de distintas coloraciones-; la utilidad de estas cubetas es difícil de precisar aunque podrían servir de alacenas o, como se ha propuesto en otros casos similares, para amasar el pan. En este poblado se ha realizado un buen estudio a nivel micro que ha permitido determinar la posible utilidad de cada recinto y confirmar la existencia de unidades funcionales formadas por más de un recinto (Fenández y Hornero 1990; Fernández Martínez et al. 1994: 121):

-Unidad 9-11: centro de reunión-ritual-textil (enterramientos infantiles, puerta decorada y gran número de fusayolas).

-Unidad 7-8-10: elaboración de alimentos (2 hogares, molinos de mano, un posible horno y tres cubetas).

-Unidad 2-6-16: cocina propiamente dicha (un hogar y una cubeta de gran tamaño, además de un basurero y abundante cerámica rota a mano).

Junto a estos yacimientos, que suponen una continuación de los ocupados en la fase anterior, se documentan otros que únicamente serán poblados a partir del siglo IV a.C., como las motillas de las 
Cañas, la de Los Palacios y la del Retamar, que, tras haber sido abandonadas a finales del Bronce Medio, vuelven a ser ocupadas en este momento. En la de Las Cañas se han encontrado varios fragmentos de cerámicas griegas que permiten fechar este momento en el siglo IV a.C. (Molina et al. 1983: 312).

En la motilla de los Palacios también se ha encontrado, procedente de excavaciones clandestinas, un fragmento de copa griega de tipo Cástulo fechable a comienzos del siglo IV a.C. (López Rozas 1987: 346). Las excavaciones de la Motilla del Retamar han permitido documentar una fase ibérica con cerámicas a torno pintadas, grises, monedas, etc., que aparecen asociadas a estructuras de habitación, entre las que cabe destacar una rampa de acceso (Galán y Sánchez Meseguer 1994: 97).

También a este momento cultural se adscribe la ocupación más antigua del Cerro de Oreto, situado en Granátula de Calatrava sobre el valle del río Jabalón. Los materiales arqueológicos, entre los que destacan las cerámicas a torno ibéricas pintadas y o estampilladas y en menor número las griegas, permiten confirmar la fecha del siglo IV a.C. para la primera ocupación del asentamiento. Este poblado continuará su desarrollo hasta la época republicana. La ubicación del cerro en un valle de gran rendimiento agrícola, unido a la cercanía de centros mineros de gran importancia y su situación geográfica, le confieren unas características propicias para alcanzar un gran desarrollo y de hecho algunos autores han identificado este yacimiento con la ciudad de Oretum Germanorum, sin embargo las excavaciones arqueológicas llevadas a cabo en el yacimiento, a todas luces insuficientes, no permiten mantener esta adscripción a sus investigadores (Nieto Gallo et al. 1980).

El número de asentamientos considerados "genéricamente" como ibéricos y localizados hasta hoy se eleva a unos doscientos, pero al conocerse la mayoría por prospecciones resulta muy difícil establecer el período exacto de desarrollo, si bien el hallazgo de cerámicas griegas en superficie en algunos de ellos como Alhambra, Valdarachas (Ciudad Real), Pradillo del Moro (Membrilla), El Morrón (Torre de Juan Abad) y Los Toriles (Villarrubia de los Ojos) permite situarlos en esta fase cultural.

Aunque existen muchas variantes, la norma general de los principales núcleos de ocupación ibéricos es que se asienten sobre cerros aislados o en lugares elevados de difícil acceso, siempre próximos a los valles de los ríos, que permiten dominar amplias zonas de vega. La mayor parte de los asentamientos se sitúan a menos de $500 \mathrm{~m}$ de algún recurso hídrico, fundamentalmente cursos fluviales, ya que éstos, además de posibilitar el aprovisionamiento de agua y la existencia de suelos aluviales fértiles, constituyen buenas vías naturales de comunicación (Tabla 1).

La altitud a la que se encuentran los poblados está determinada por la geomorfología del terreno: en la zona del Campo de Calatrava la altitud sobre el nivel del mar se sitúa en torno a los $700 \mathrm{~m}$, como ocurre en Alarcos y La Bienvenida, mientras en la zona del Campo de Montiel los poblados se ubican a mayor altitud, entre 800 y $1000 \mathrm{~m}$, como comprobamos en el Cerro de las Cabezas, Alcubillas y Almedina. En la zona manchega propiamente

\begin{tabular}{|l|l|l|l|}
\hline \multicolumn{1}{|c|}{$\begin{array}{c}\text { Yacimientos } \\
\text { próximos a ríos }\end{array}$} & \multicolumn{1}{|c|}{$\begin{array}{c}\text { Yacimientos } \\
\text { sobre ríos }\end{array}$} & \multicolumn{1}{c|}{$\begin{array}{c}\text { Yacimientos } \\
\text { próximos a lagunas }\end{array}$} & \multicolumn{1}{c|}{$\begin{array}{c}\text { Yacimientos } \\
\text { próximos a arroyos }\end{array}$} \\
\hline $\begin{array}{l}\text { Alarcos } \\
\text { Cerro de las Cabezas }\end{array}$ & & & $\begin{array}{l}\text { Pozo de la Nava } \\
\text { Los Rubiales } \\
\text { Toriles }\end{array}$ \\
Mentesa & & Los Villares \\
Valdarachas & Gétor \\
Oreto & Motilla de las Cañas & La Nava las Nieves & Las Manzanas I \\
Calatrava la Vieja & & Moraleja III & Tobares III \\
Cantagallos & Castillo de Caracuel & Arroyo Mordancho II \\
San Cristobal & & & Cortijo del Bailarín \\
Molino de los Moros & & & Los Boquerones II \\
& & & Las Fuentes \\
\hline
\end{tabular}

Tabla 1.- Relación entre los asentamientos ibéricos y los recursos hídricos próximos. 
dicha, al carecer de alturas destacadas, se aprovechaba cualquier promontorio que sobresale del llano, y así se explicaría que las motillas sean reaprovechadas y vuelvan a ser ocupadas en este momento. En función de su ubicación podemos diferenciar dos grandes tipos de asentamientos (Tabla 2).

\begin{tabular}{|l|l|}
\hline \multirow{5}{*}{ ALTURA } & \multicolumn{1}{|c|}{ Sobre promontorio elevado } \\
\cline { 2 - 2 } & $\begin{array}{l}\text { Cerro de las Cabezas, Alarcos, Oreto, } \\
\text { Almedina, Mentesa, Castillo de Alcubillas, } \\
\text { El Morrón, Alhambra, Los Minguitos, } \\
\text { Cerro de Navalromo }\end{array}$ \\
\cline { 2 - 2 } Sobre promontorio poco elevado \\
\cline { 2 - 2 } Lerro de las Nieves, Calatrava la Vieja, La \\
$\begin{array}{l}\text { Bienvenida, Castilnovo, La Minilla, } \\
\text { Puente de las Ovejas, Moraleja I, Monte } \\
\text { Máximo, Tobares III, Las Fuentes }\end{array}$ \\
\hline \hline & $\begin{array}{l}\text { Valdarachas, Casa de Rana, Buenavista, } \\
\text { Renales, Toriles, Puédrola, Cortijo de la } \\
\text { Caridad, Aldea de Santa María, Gétor, } \\
\text { Lote, Cantagallos, Blanquillo, Molino de } \\
\text { los Moros, Los Farrales I, La Nava, } \\
\text { Cominar }\end{array}$ \\
\hline
\end{tabular}

Tabla 2.- Los dos tipos de asentamiento ibérico en función de su altura.

Además de los factores anteriores, el desarrollo de los grandes oppida en esta fase hay que ponerlo también en relación con los factores económicos, pues de ellos dependía la prosperidad de unos asentamientos que una vez incorporados a los circuitos comerciales coloniales debían asegurar el aporte de las materias primas codiciadas por griegos y fenicios: los productos agropecuarios y mineros. De este modo observamos que poblados como Alarcos, el Cerro de las Cabezas, Oreto o Calatrava la Vieja se sitúan en áreas muy ricas para la explotación agrícola y ganadera, La Bienvenida explica su desarrollo por la riqueza minera de la zona (cinabrio, plomo y plata) y núcleos como el Cerro de las Nieves y el Santuario de la Virgen de Criptana posiblemente explotarían otro recurso fundamental en la antigüedad como la sal.

La progresiva complejidad y prosperidad que iban adquiriendo los poblados ibéricos, sobre todo en su etapa de máximo desarrollo, tuvo que llevar aparejada una mayor preocupación por la seguri- dad. Una accesibilidad difícil y la presencia de defensas naturales fueron elementos importantes a la hora de elegir emplazamiento, pero en muchos casos se optó por reforzar la seguridad mediante sistemas defensivos artificiales cuya presencia es una característica inherente a la propia definición de oppidum, término que en un sentido etimológico estricto tan solo debería aplicarse a los poblados fortificados aunque se tiende a una definición conceptual más amplica que entiende el oppidum como una unidad política y económica, con jerarquización social, espacios de poder, modulación espacial, etc. (Ruiz Rodríguez 1998: 87).

El único sistema defensivo documentado en la zona es la muralla (Fig. 10), siendo la mejor conocida la del Cerro de Las Cabezas cuya primera línea se levantará en el siglo V a.C. y se verá reforzada por otra línea en los siglos IV-III a.C. La muralla del siglo $\mathrm{V}$ a.C., que presenta un grosor medio de 4-5 $\mathrm{m}$ y un perímetro de unos $1750 \mathrm{~m}$, se adapta a la irregular topografía del terreno y en muchos casos se apoya sobre la roca. La técnica constructiva consiste en levantar dos muros de piedra de unos 70-80 cm de grosor, unidos entre sí por muros paralelos de menores dimensiones $-40 \mathrm{~cm}$ de grosor- rellenando el hueco que queda entre estos muros con piedras de pequeño y mediano tamaño trabadas con argamasa de arcillas y cal en la que se intercalan pequeños guijarros. En esta fase el sistema defensivo se completaba con la alternancia de bastiones cuadrangulares y circulares adheridos a la muralla. En el siglo IV a.C. las líneas de muralla, sobre todo las de las zonas bajas del poblado, sufren modificaciones al emplearse un sistema ciclópeo con grandes bloques de pie-

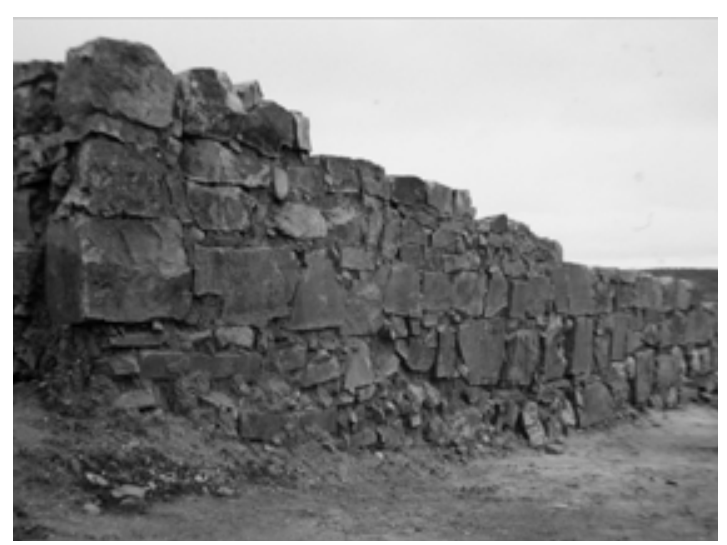

Figura 10.- Muralla del Cerro de las Cabezas (Valdepeñas). 
dras escuadradas que soportan paramentos de adobes y tapiales (Vélez y Pérez Avilés 2000: 141-142).

En La Bienvenida se ha identificado una muralla de casamatas fechada entre el Ibérico Pleno y el Ibérico Final (Zarzalejos et al. 2004: 169-170). En la motilla de Las Cañas se ha localizado una muralla de época ibérica que rodea el asentamiento de la Edad del Bronce, compuesta por grandes bloques de piedra con un refuerzo exterior que le permitía alcanzar una anchura de 4,30 m (Molina et al. 1983: 308).

En el cerro de Alarcos se han encontrado en varias zonas restos de muros de grandes dimensiones, en ocasiones parcialmente destruidos por la muralla medieval, que podrían corresponder al sistema de fortificación del oppidum. La línea defensiva de época ibérica podría haber sido seguida o reaprovechada en parte por la muralla medieval, cuyo trazado también estaría condicionado por la orografía del terreno. El aprovechamiento del trazado de la muralla ibérica para la edificación de la muralla medieval también parece constatarse en Calatrava la Vieja. En otros yacimientos prospecta- dos se aprecian concentraciones de piedras que podrían responder a líneas de fortificación, pero sería preciso efectuar sondeos para poder confirmar su vinculación a estructuras defensivas y valorar a qué momento concreto de época ibérica se pueden adscribir.

\section{Modelo de Poblamiento (Fig. 11)}

Evidentemente la disposición y distribución de los asentamientos en el territorio correspondiente al Alto Guadiana está condicionada por las características particulares de su relieve, pero existen unos criterios comunes a la hora de organizar el poblamiento, los cuales vienen marcados por unos intereses comunes, representados por las aristocracias que, en definitiva, serán las responsables del patrón de ocupación del territorio adoptado, el cual no respondería a una estructuración prefigurada de antemano sino que se iría configurando de forma progresiva en función de las necesidades que iban

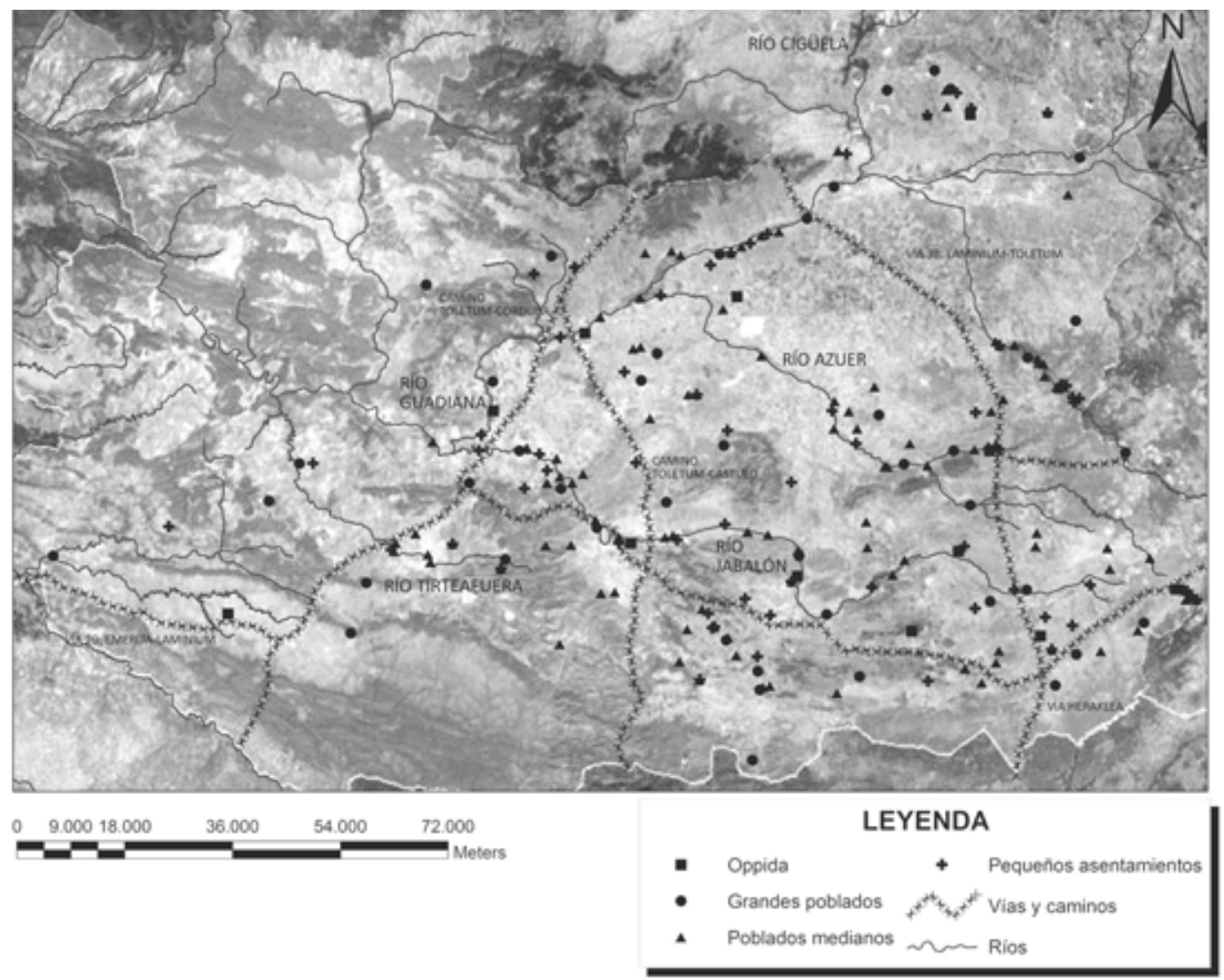

Figura 11.- Mapa de dispersión de los distintos tipos de asentamiento. 
surgiendo con el paso del tiempo. Atendiendo al tamaño aproximado de los lugares de hábitat de nuestro ámbito de estudio en época ibérica hemos podido diferenciar cuatro tipos de asentamientos, que describimos a continuación.

\subsection{Oppida (superiores a 6 hectáreas) (Fig. 12)}

Se trata de 12 poblados de gran notoriedad que, por lo general, se sitúan a una distancia media entre ellos que oscila entre los 20 y los $30 \mathrm{~km}$. Además de su destacada extensión presentan características comunes como su localización en lugares que destacan notablemente sobre el terreno circundante. Esta disposición respondería a una doble función: defensiva y de control, tanto de los recursos localizados en las proximidades como de las vías de comunicación. Todos los asentamientos se sitúan a menos de $5 \mathrm{~km}$ de alguna destacada ruta $\mathrm{y}$, en muchos casos, estas importantes vías de comunicación discurren a una distancia inferior a 1 $\mathrm{km}$. También es común a este tipo de poblados la proximidad a importantes recursos hídricos, preferentemente ríos, entre los que destacan el Guadiana y el Jabalón, aunque en algunos casos el aporte de agua estaría vinculado a la presencia de otro tipo de recursos como los arroyos, manantiales y acuíferos.

En este tipo de poblados se constata la presencia de importantes construcciones como murallas, calles pavimentadas, santuarios, etc., cuya edificación requería un esfuerzo colectivo que debería estar organizado por los grupos dirigentes. De hecho algunas de estas edificaciones, como las áreas de culto de Alarcos y de El Cerro de las Cabezas, podrían ser considerados "espacios de poder vinculados a la residencia aristocrática" (Ruiz Rodríguez 1998: 87; Ruiz Rodríguez 2007). La presencia de este tipo de jefaturas no sólo se pone de manifiesto por la existencia de notables edificaciones sino también por la presencia de destacados objetos de prestigio -cerámicas importadas, objetos de orfebrería, representaciones plásticas-, que hasta el momento se han documentado en casi todos los oppida de esta zona.

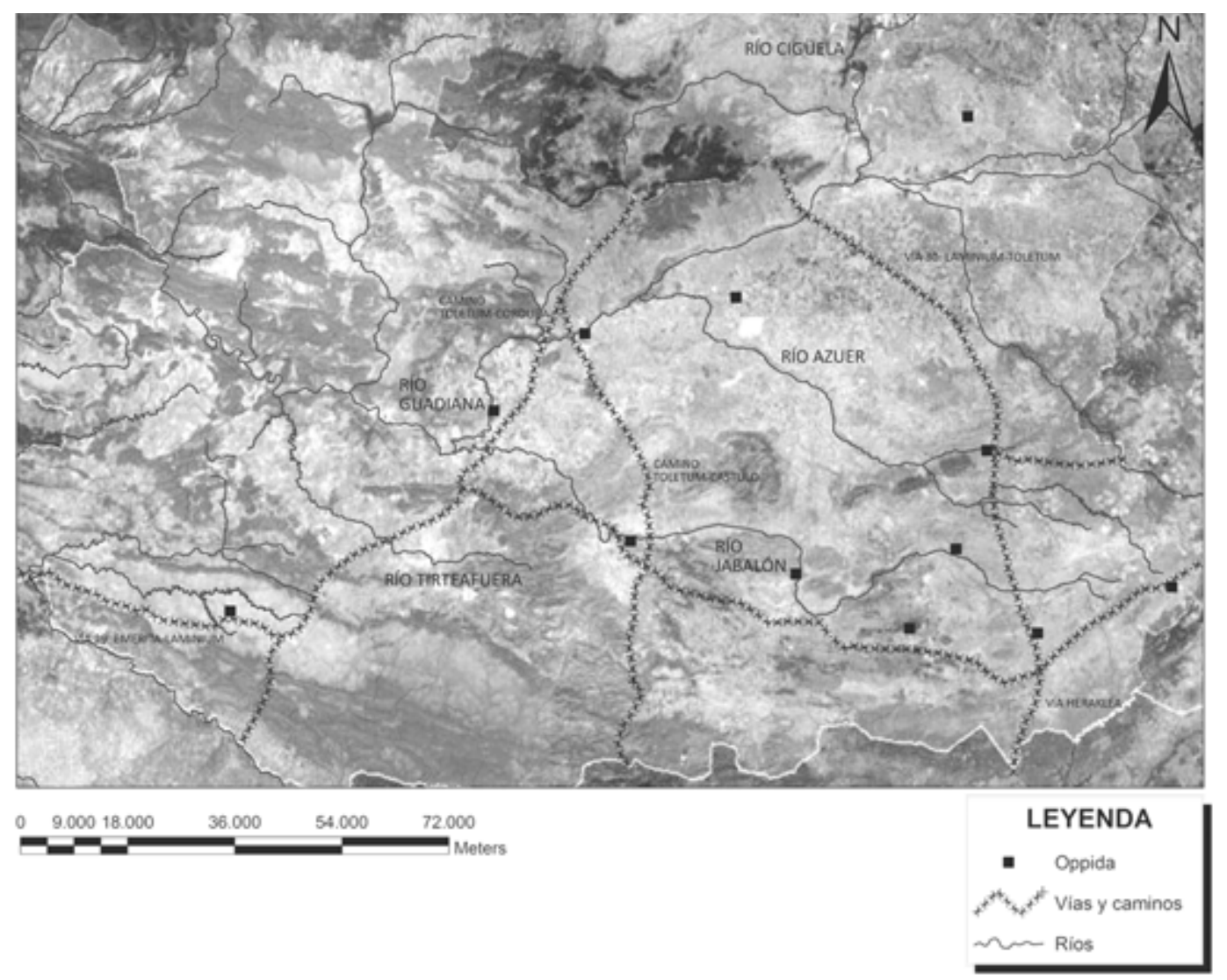

Figura 12.- Mapa de dispersión de los oppida 
Es significativo constatar que la práctica totalidad de los asentamientos de este grupo iniciaron su ocupación en época preibérica, es decir, protagonizaron el cambio en el patrón de poblamiento producido a lo largo del Bronce Final-Hierro I, que supuso una completa modificación con respecto a la organización territorial definida durante el Bronce Antiguo y Pleno. Todo parece apuntar a que la transformación en el modelo de ocupación del territorio estaría protagonizada por estos grandes poblados, más concretamente por las jefaturas en ellos asentadas, que optan por una nueva planificación espacial, de modo similar a como sucede en otros ámbitos peninsulares de forma contemporánea, como respuesta a una serie de influjos procedentes del exterior, en un primer momento atlánticos y posteriormente de carácter mediterráneo, que exigen una organización socioeconómica diferente a la desarrollada hasta entonces y que dará lugar a la delimitación o intensificación de nuevas rutas y áreas de captación económica que serán controladas desde estos nuevos poblados, lo que acabará constituyendo "la mejor expresión del espacio político definido por la aristocracia ibérica" (Ruiz Rodríguez 1998: 77).

La estructuración configurada durante la fase preibérica se mantendrá prácticamente sin cambios destacables a lo largo de todo el período ibérico, llegando incluso en algunos casos a perpetuarse hasta la época romana, pues si bien algunos de estos oppida fueron abandonados o perdieron su protagonismo, como en el caso de Alarcos y Calatrava la Vieja, otros mantuvieron o incrementaron su importancia, lo que posibilitó que su existencia pudiera ser recogida en diversas fuentes clásicas con una denominación conocida: Oretum, Mentesa, Sisapo, Laminium, etc.

\subsection{Grandes poblados (entre 1 y 5 hectáreas) (Fig. 13)}

Hasta el momento se incluyen en este grupo unos 40 asentamientos, que suelen estar vinculados a algún oppidum del que, por término medio, se

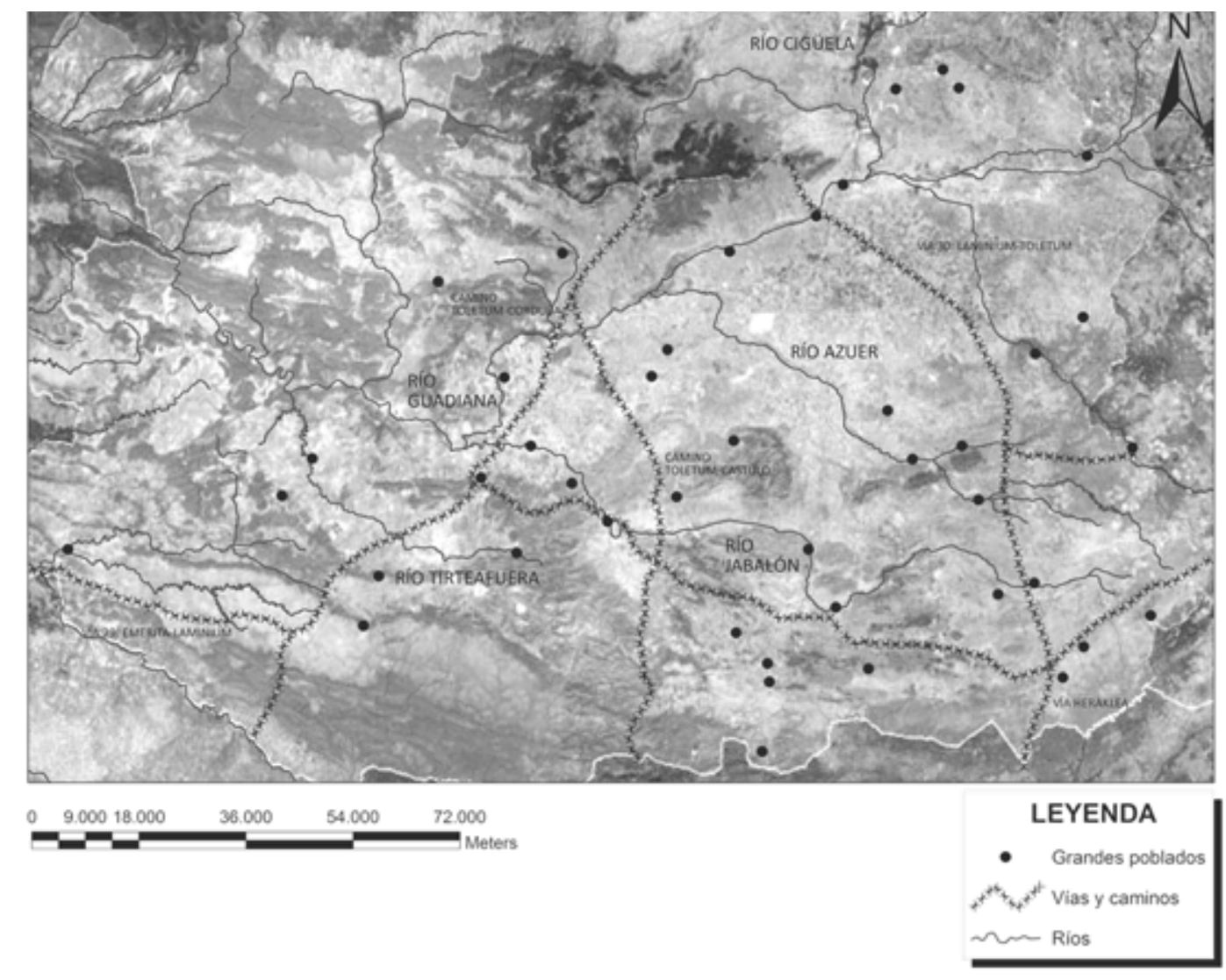

Figura 13.- Mapa de dispersión de asentamientos grandes 
encuentran a una distancia que oscila entre los 6 y los $10 \mathrm{~km}$. Pueden aparecer en tres tipos de disposiciones básicas: sobre elevados promontorios, sobre discretas elevaciones o en terrenos llanos. El hecho de que no exista un tipo de localización predominante, como sucede en el caso de los oppida, presenta cierta lógica ya que estos asentamientos al ser más numerosos ocupan más densamente el territorio, contribuyendo a lograr una vertebración más equilibrada que permite controlar áreas más diversas como montes y valles, sobre las que resultaba complejo ejercer un control directo desde los oppida principales.

Según la ubicación concreta de cada uno de estos grandes asentamientos, podría predominar el factor estratégico y de control del terreno circundante en aquellos situados sobre destacados promontorios y la función de explotación económica del entorno en los localizados en zonas más llanas. No obstante, estimamos que la disposición de estos destacados asentamientos tuvo entre sus fines primordiales ampliar y consolidar la extensión territorial del área de influencia de los oppida y, consiguientemente, de las jefaturas en ellos establecidas, quienes a cambio suministrarían una serie de producciones artesanales más elaboradas y objetos de prestigio importados, lo cual se puede rastrear arqueológicamente a través de elocuentes indicios como la presencia de materiales cerámicos de factura muy similar en grandes poblados y en sus oppida más próximos como sucede, por ejemplo, entre Valdarachas y Alarcos.

Un tercio de estos grandes poblados ofrecen muestras materiales que permiten intuir la posible existencia de una fase de ocupación preibérica, por lo que se puede inferir que probablemente formaron parte del nuevo patrón de asentamiento que, bajo las líneas maestras determinadas por los oppi$d a$, empezó a configurarse a partir del Bronce Final. De todos modos, parece que tras el inicio de la iberización se consolidó la aparición de este tipo de asentamientos con el fin de reforzar la labor de control y de explotación económica desarrollada por los oppida. Muchos de los grandes poblados mantendrían un protagonismo destacado en época romana, llegando incluso a adquirir en esta etapa una mayor importancia en el poblamiento como se pone de manifiesto en el caso de Miradores, Mairena y la Virgen de la Cabeza.

Complutum, 2011, Vol. 22 (1): 155-176

\subsection{Asentamientos medianos (entre 0,2 y 0,9 hec- táreas) (Fig. 14)}

Constituye el conjunto más numeroso al integrar aproximadamente un centenar de yacimientos que, como en el caso de los oppida, se concentran en la mitad oriental de la provincia. La distancia media entre ellos oscila entre 2 y $5 \mathrm{~km}$, si bien en algunas zonas que han sido objeto de labores de prospección más intensas -tramos de los ríos Jabalón, Cigüela y Guadiana- la distancia media es menor, entre 1,5 y $3 \mathrm{~km}$.

Gran parte de este tipo de asentamientos se ubican en suaves elevaciones o terrenos llanos, generalmente en zonas bastante adecuadas para la explotación agraria, lo cual permite explicar en cierto modo el hecho de que este tipo de poblados no esté poco representado en las comarcas de los Montes y de Alcudia-Sierra Morena, cuyos terrenos no resultan muy aptos para la explotación agrícola. En algunos casos también se localizan próximos a minas o a concentraciones salinas, circunstancias que probablemente tendrían cierta influencia a la hora de determinar su ubicación y posterior desarrollo. Dentro del análisis del tipo de situación elegida para este tipo de asentamiento debemos destacar la importancia que adquieren ciertas elevaciones artificiales, concretamente las motillas de la Edad del Bronce, muchas de las cuales serán reocupadas durante el Ibérico Pleno.

En principio, la menor extensión superficial de los denominados asentamientos medianos parece remitirnos a una menor complejidad en su organización interna. No obstante, debemos indicar que algunos de estos asentamientos que han sido objeto de excavaciones sistemáticas ofrecen notables estructuras defensivas como se aprecia en la Motilla de la Cañas, presentan una incipiente planificación urbanística como en el caso de Peñarroya o se ha podido comprobar la existencia de una diferenciación funcional entre los distintos recintos excavados como en el Cerro de las Nieves.

Hasta el momento tan sólo un $20 \%$ de los asentamientos medianos parecen registrar una fase de ocupación anterior al Ibérico Pleno, lo cual parece indicar que sería en este momento cuando se desarrollarían más profusamente este tipo de poblados en nuestro ámbito de estudio, lo cual podría estar relacionado con un probable crecimiento demográfico durante esta fase y con la creciente necesidad de una intensificación de la explotación económica 


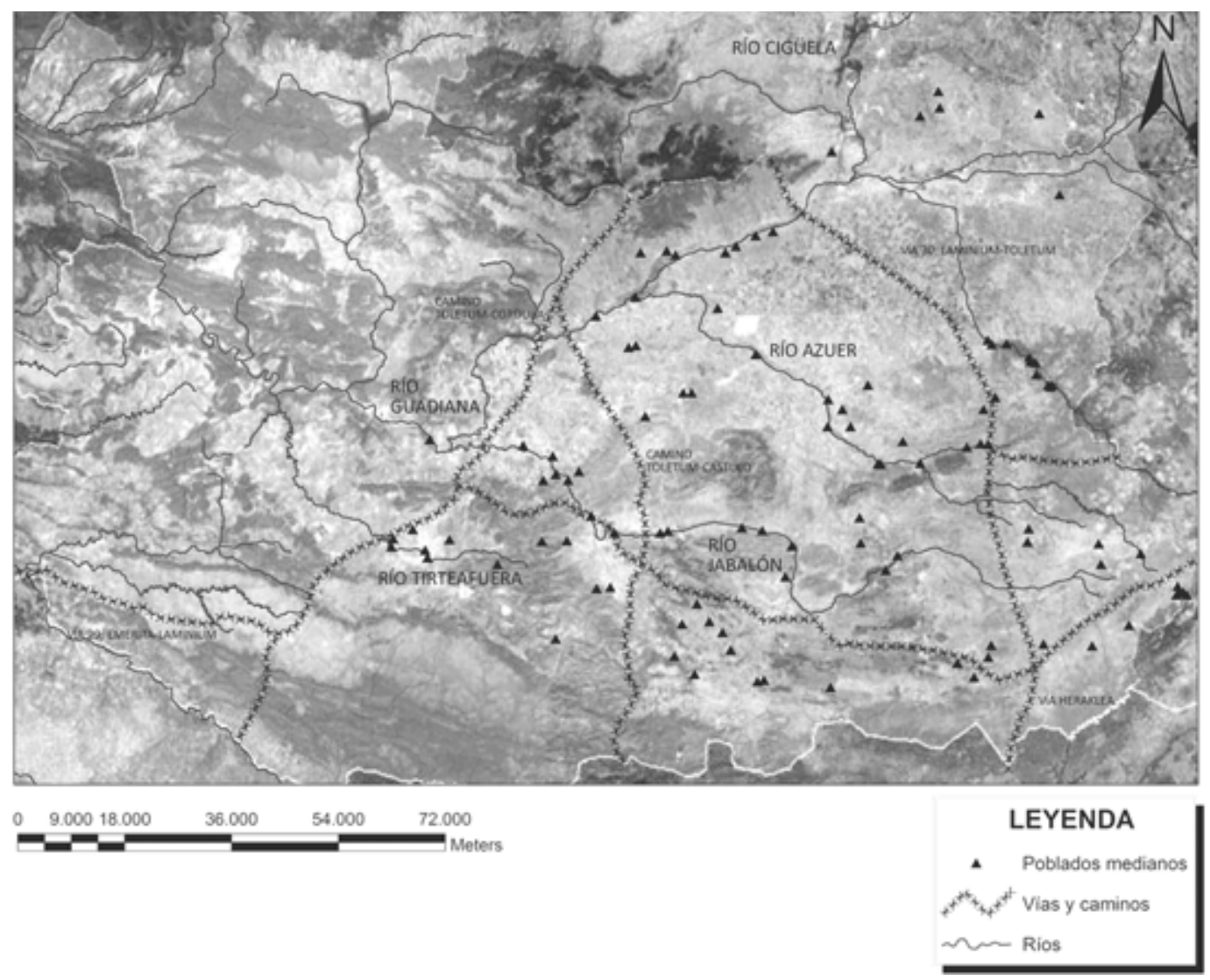

Figura 14.- Mapa de dispersión de asentamientos medios.

para hacer frente a un incremento de la demanda exterior y así poder asegurar la llegada y redistribución de objetos de prestigio, que en algunos casos también aparecen en los asentamientos medianos.

Por otra parte, resulta bastante significativo el elevado porcentaje (en torno al $60 \%$ ) de asentamientos de este grupo que muestra una continuidad de ocupación durante la época romana, hecho que debe ser puesto en relación con el tipo de emplazamiento elegido preferentemente por este tipo de poblados, que mantendrá plena vigencia tras la ocupación romana de este ámbito de la meseta sudoccidental.

\subsection{Pequeños asentamientos (menos de 0,2 hec- táreas) (Fig. 15)}

Dada la reducida extensión superficial de este tipo de asentamientos resulta muy compleja su visualización en labores de prospección, por lo cual estimamos que los cerca de 40 yacimientos documentados representan una muestra algo parcial.

A pesar de contar para su caracterización tan sólo con datos procedentes de prospecciones superficiales podemos constatar una serie de patrones bastantes homogéneos, entre los que destacan que no se localizan en lugares elevados, siendo bastante habitual que se ubiquen sobre terrazas fluviales. Se trataría de pequeñas agrupaciones de viviendas en las que habitaría un reducido contingente de población, que, al gozar de una evidente facilidad para aprovechar las apropiadas condiciones que ofrecen las vegas de ríos y arroyos en cuyo entorno se establecen, tendría como actividad básica la explotación agropecuaria, la cual estaría fundamentalmente destinada al autoabastecimiento al no poder generar importantes excedentes una población tan escasa; en este sentido resulta significativo que, hasta el momento, no se hayan documentado en estos asentamientos importaciones o elementos de prestigio.

Estos asentamientos no han aportado materiales que puedan ser adscritos a una fase preibérica o 


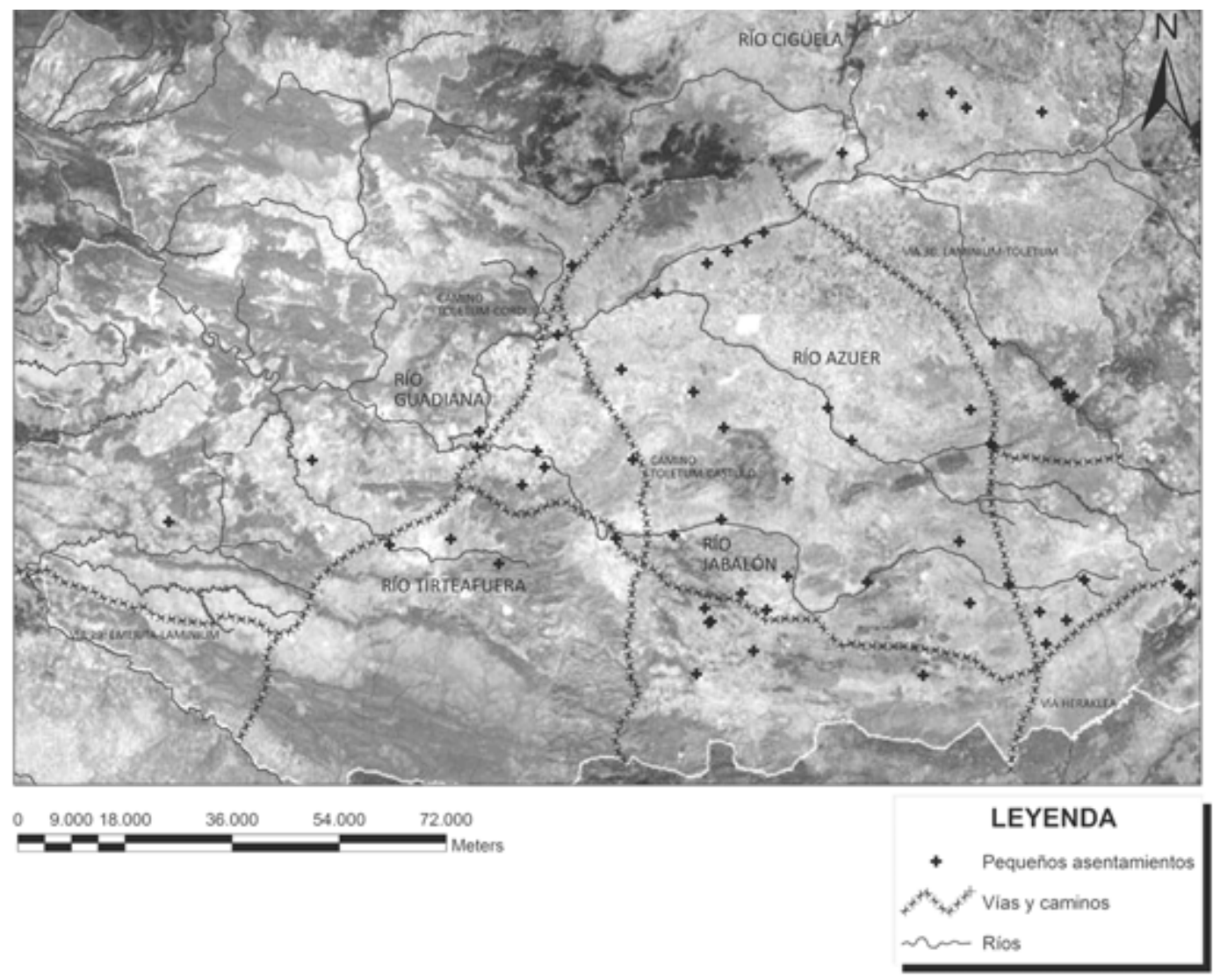

Figura 15.- Mapa de dispersión de asentamientos pequeños

correspondiente al Ibérico Antiguo. El elemento más común es la presencia de típicas cerámicas ibéricas decoradas con motivos geométricos pintados que, en ocasiones, presentan una factura poco cuidada, hecho que podría relacionarse con la menor entidad de este tipo de asentamientos o con una posible elaboración en una fase de cierta decadencia encuadrable en el Ibérico Final. Nuestra percepción nos lleva a plantear que un elevado porcentaje de estos pequeños núcleos de población pudo iniciar su desarrollo en un momento final del proceso de expansión demográfica y ocupación de este territorio por parte de los grupos iberos aquí asentados, que verán truncado este proceso expansivo al quedar inmersas estas tierras dentro del juego de los intereses enfrentados de romanos y cartagineses. No obstante, todo parece indicar que estos asentamientos no se vieron muy afectados por la conflictividad derivada de la Segunda Guerra Púnica y el posterior proceso de conquista romana, ya que la amplia mayoría de estos pequeño núcleos de población (en torno al 90\%) presen- tan una continuidad en época romana -en ocasiones experimentado un considerable incremento de su área superficial-, probablemente al responder su tipo de localización al sistema de explotación económica implantado por Roma en este territorio.

\section{Conclusiones}

La disposición espacial de los tipos de asentamientos anteriormente comentados dio lugar a la configuración de una red jerarquizada e interrelacionada de poblados, cuya estructuración respondería a los intereses de las jefaturas establecidas en los principales oppida. El establecimiento de este modelo jerárquico en la organización de nuestro ámbito de estudio en época ibérica no es el resultado de una concepción prefigurada sino que se fue constituyendo de forma progresiva, casi "orgánica", para dar respuesta a las necesidades que iban surgiendo con el paso del tiempo, teniendo siempre como referente las características físicas de cada 
una de las comarcas naturales que integran este territorio meseteño.

Este modelo de poblamiento se mantendría en líneas generales hasta fines del siglo III a.C., momento en el que se van a producir en este ámbito territorial, al igual que en buena parte de la Península, una serie de transformaciones que, en gran medida, deben ser puestas en relación con el período de crisis ocasionado por la llegada de las tropas cartaginesas. Es posible que se pueda relacionar con este hecho el abandono de algunos asentamientos como la motilla de las Cañas, el Cerro de Las Nieves o el Cerro de Las Cabezas. Otros oppida importantes como Alarcos mantendrán un poblamiento más reducido durante parte de la etapa republicana romana, sin llegar al cambio de era. Finalmente la continuidad en el poblamiento hasta la época imperial está atestiguada en otros oppida como La Bienvenida, Mentesa y Oreto, aunque en ocasiones esta ocupación provocará, caso de Oreto, un traslado o una ampliación del área de hábitat.

\section{REFERENCIAS BIBLIOGRÁFICAS}

Almagro Gorbea, M. (1977): La iberización de las zonas orientales de la Meseta. Simposi Internacional: Els Origens del Món Ibèric. Ampurias, 38-40: 93-156.

Berrocal-Rangel, L. (1992): Los pueblos célticos del Suroeste de la Península Ibérica. Complutum Extra 2. Universidad Complutense, Madrid.

Blasco Bosqued, C. (1992): Etnogénesis de la Meseta Sur. Paleoetnología de la Península Ibérica (M. AlmagroGorbea, G. Ruiz Zapatero, eds.), Complutum, 2-3, Universidad Complutense, Madrid: 281-297.

Bonet Rosado, H; Mata Parreño, C. (2001): Organización del territorio y poblamiento en el País Valenciano entre los siglos VII al II a.C. Entre Celtas e Iberos. Las poblaciones protohistóricas de las Galias e Hispania (L. BerrocalRangel y P. Gardes, eds.), Real Academia de la Historia, Casa de Velázquez, Madrid: 175-186.

Caballero Klink, A.; Mena, P. (1987): Los exvotos ibéricos del oppidum de Alarcos. XVIII Congreso Nacional de Arqueología, Zaragoza: 615-633.

Ciudad, A.; Serrano, J. (1986): Poblamiento y culturas en la Prehistoria. La Historia de la Provincia de Ciudad Real, Diputación Provincial de Ciudad Real: 5-31.

De Juan García, A.; Fernández, M.; Caballero, A. (1994): El yacimiento ibero-medieval de Alarcos. Arqueología en Ciudad Real, Patrimonio Histórico Arqueología Castilla-La Mancha, 8, Junta de Comunidades de Castilla-La Mancha, Toledo: 143-165.

Domergue, C. (1967): La mine antique de Diogenes (province de Ciudad Real). Melanges de la Casa de Velasquez, III: 29-91.

Fernández Maroto, D.; Vélez Rivas, J.; PÉrez AvilÉs, J.J. (2007): La cerámica estampillada ibérica de tipo figurativo del Cerro de las Cabezas (Valdepeñas). Arte Ibérico en la España Mediterránea (L. Abad y J. Soler, eds.), Instituto Alicantino de Cultura Juan Gil Albert, Diputación Provincial de Alicante: 185-209.

Fernández Martínez, V.M. (1988): El asentamiento ibérico del Cerro de las Nieves (Pedro Muñoz, Ciudad Real). I Congreso de Historia de Castilla la Mancha, Tomo III, Junta de Comunidades de Castilla-La Mancha, Ciudad Real: 359-369.

Fernández Martínez, V.M.; Hornero del Castillo, E. (1990): Análisis funcional de los recintos domésticos del poblado ibérico del Cerro de las Nieves (Pedro Muñoz, Ciudad Real). Espacio y Organización Social (J. Adánez, C. Heras, C. Varela, eds.) Universidad Complutense de Madrid, Estudios de Geografía e Historia, Madrid: 163-178.

Fernández Martínez, V.M.; Hornero del Castillo, E.; Pérez Muga, J. (1994): El poblado ibérico del Cerro de las Nieves (Pedro Muñoz). Excavaciones 1984-1991. Arqueología en Ciudad Real. Patrimonio Histórico Arqueología Castilla-La Mancha, 8, Junta de Comunidades de Castilla-La Mancha. Toledo: 111-129.

Fernández OchoA, C.; Zarzalejos, M,; Hevia, P.; Gómez; Esteban, G. (1994): Sisapo I. Excavaciones arqueológicas en La Bienvenida. Almodóvar del Campo (Ciudad Real). Patrimonio Histórico-Arqueología Castilla-La Mancha, 10. Junta de Comunidades de Castilla-La Mancha. Toledo.

FERnÁndez Rodríguez, M. (2001): La necrópolis del Sector IV de Alarcos (Ciudad Real). Arqueología Funeraria: las necrópolis de incineración (R. García Huerta y J. Morales, eds.), Ediciones de la Universidad de Castilla-La Mancha, Cuenca: 259-284.

Fernández Rodríguez, M.; FonsecA, R. (1985): Materiales ibéricos de la Motilla de los Palacios (Ciudad Real). Oretum, I: 257-275.

FernÁndez Rodríguez, M. ET AL. (1995): Constantes de poblamiento en el cerro de Alarcos. Alarcos 1195: El fiel de la Balanza (Catálogo de la exposición), Ediciones de la Universidad de Castilla-La Mancha, Ciudad Real: 27-40.

Fernández Rodríguez, M.; García Huerta, R. (1998): El urbanismo del poblado ibérico de Alarcos (Ciudad Real). Los Iberos, Príncipes de Occidente, Fundació La Caixa, Barcelona: 47-55. 
Fernández Rodríguez, M.; Rodríguez de la Esperanza, M.J. (2002): Los depósitos de armas en el Bronce Final: un nuevo hallazgo en Puertollano (Ciudad Real). Trabajos de Prehistoria, 59: 113-133.

Galán Saulnier, C.; SÁnchez Meseguer, J. (1994): Santa María del Retamar.1984-1991. Arqueología en Ciudad Real. Patrimonio Histórico-Arqueología Castilla-La Mancha, 8, Junta de Comunidades de Castilla-La Mancha. Toledo: 87-110.

García Huerta, R.; Fernández Rodríguez, M. (2000): La génesis del Mundo Ibérico en la submeseta sur: El tránsito Bronce Final-I Edad del Hierro en Alarcos. Cuadernos de Prehistoria y Arqueología de la Universidad Autónoma de Madrid, 26: 47-68.

García Huerta, R.; Morales, J.; OcAÑA A. (1999): El poblado de la Edad del Hierro de Peñarroya, Argamasilla de Alba, Ciudad Real. I Jornadas de Arqueología Ibérica en Castilla la Mancha. Patrimonio Histórico-Arqueología Castilla-La Mancha, 14, Junta de Comunidades de Castilla-La Mancha. Toledo: 221-258.

García Huerta, R.; Morales, J.; Rodríguez, D. (2004): La cerámica griega del oppidum ibérico de Alarcos (Ciudad Real). Charisterion, Francisco Martín García oblatum (I.J. García; S. Talavera, eds.), Ediciones de la Universidad de Castilla-La Mancha, Cuenca: 115-130.

García Huerta, R.; Morales, J.; Vélez, J.; Soria, L.; Rodríguez, D. (2006): Hornos de pan en la Oretania Septentrional. Trabajos de Prehistoria, 63 (1): 157-166.

García Huerta, R., Morales Hervás, J. (2009): Sistemas de almacenamiento y tratamiento de alimentos entre los pueblos prerromanos en la meseta meridional. Sistemas de almacenamiento entre los pueblos prerromanos (R. García Huerta y D. Rodríguez, eds.), Ediciones de la Universidad de Castilla-La Mancha, Cuenca: 167-208.

Grau Mira, I. (2002): La organización del territorio en el área central de la Contestania Ibérica. Universidad de Alicante, Alicante.

LÓPEz RozAs, J. (1987): El poblamiento ibérico en la Meseta Sur. Iberos. I Jornadas sobre el mundo ibérico (A. Ruiz; M. Molinos, eds.), Junta de Andalucía, Jaén: 335-347.

Molina, F. ET AL. (1983): La Motilla de las Cañas (Daimiel, Ciudad Real). Campaña de 1983. Cuadernos de Prehistoria de la Universidad de Granada, 8: 301-324.

Montero Ruiz, I.; Fernández Rodríguez, M.; Gómez Tubio, B.; Ontalba Salamanca, M.A. (2002): Espadas y puñales del bronce final: el depósito de armas de Puertollano (Ciudad Real). Gladius, 22: 5-28.

Morales Hervás, F.J. (2010): El Poblamiento de la época ibérica en la provincia de Ciudad Real. Ediciones de la Universidad de Castilla-La Mancha, Cuenca.

NÁJera, T.; Molina. F. (1977): La Edad del Bronce en La Mancha. Excavaciones en las motillas del Azuer y Los Palacios (Campaña de 1974). Cuadernos de Prehistoria de la Universidad de Granada, 2: 251-282.

Nieto Gallo, G.; SÁnchez Meseguer, J.; Poyato, C. (1980): Oreto I. Excavaciones Arqueológicas en España, 114. Madrid.

PÉREZ, C.J. (1987): Materiales arqueológicos del Bronce, ibéricos y romanos de Almedina (Ciudad Real). Resultados de unas prospecciones. Oretum, III: 198-213.

PÉrez AviLÉs, J.J. (1985): Estudio arqueológico del Campo de Montiel. Oretum, I: 175-237.

Retuerce, M. (1994): Calatrava La Vieja. Diez años de investigación arqueológica. Arqueología en Ciudad Real. Patrimonio Histórico-Arqueología Castilla-La Mancha, 8, Junta de Comunidades de Castilla-La Mancha. Toledo: 211-241.

Rodríguez DíAz, A. (1995): El poblamiento prerromano en la Baja Extremadura. Tesis Doctorales, Ed. Microfichas, Cáceres.

Ruiz Rodríguez, A. (1998): Los iberos y su espacio. Los Iberos, Príncipes de Occidente, Fundació La Caixa, Barcelona: 77-89.

Ruiz Rodríguez, A. (2007): Los Iberos. De Iberia a Hispania (F. Gracia, ed.), Ariel, Barcelona: 733-839.

SORIA COMBADIERA, L. (2000): La Cultura Ibérica en la provincia de Albacete. Génesis y evolución a través del estudio del poblamiento. Colección Tesis Doctorales, Universidad de Castilla-La Mancha, Cuenca.

VÉlez RIVAS, J.; PÉRez AvilÉs, J.J. (1987): El yacimiento protohistórico del Cerro de las Cabezas. Oretum, III: 167-196.

Vélez Rivas, J.; Pérez Avilés, J.J.; Carmona, M. (2004): El Cerro de las Cabezas: una ciudad fortificada. Investigaciones Arqueológicas en Castilla-La Mancha 1996-2002. Patrimonio Histórico Arqueología Castilla-La Mancha, 18, Junta de Comunidades de Castilla-La Mancha. Toledo: 91-104.

Zarzalejos, M.; Fernández OchoA, C.; Hevia, P.; Esteban, G. (1994): Excavaciones en La Bienvenida (Ciudad Real). Hacia una definición preliminar del horizonte histórico-arqueológico de la Sisapo antigua. Arqueología en Ciudad Real, Patrimonio Histórico Arqueología Castilla-La Mancha, 8, Junta de Comunidades de Castilla-La Mancha. Toledo: 169-194.

Zarzalejos, M., Fernández OchoA, C.; Hevia, P. (2004): El Proyecto Sisapo-La Bienvenida (Almodóvar del Campo, Ciudad Real). Balance de los trabajos más recientes y nuevas perspectivas de la investigación. Investigaciones Arqueológicas en Castilla-La Mancha 1996-2002, Patrimonio Histórico Arqueología Castilla-La Mancha, 18, Junta de Comunidades de Castilla-La Mancha. Toledo.: 163-180. 